\title{
EL LEGADO DE LAS SIETE LEYES: UNA REEVALUACIÓN DE LAS APORTACIONES DEL CONSTITUCIONALISMO CENTRALISTA A LA HISTORIA CONSTITUCIONAL MEXICANA*
}

\author{
Catherine Andrews \\ Centro de Investigación y Docencia Económicas
}

\begin{abstract}
Z milio Rabasa opinaba que era "inútil examinar las ConstituCciones absolutamente ilegítimas y extravagantes de 1836 y 1843 , que no tienen interés para nuestro Derecho constitucional ni por las teorías ni por su aplicación". ${ }^{1}$ Su juicio reflejaba el consenso historiográfico de principios del siglo xx: los centralistas y conservadores formaron la oposición reaccionaria y absolutista al constitucionalismo republicano y federal. Ningún texto constitucional centralista podía ofrecer lecciones al jurista interesado en la historia constitucional mexicana ni contener antecedentes importantes del desarrollo del derecho constitucional en el siglo XIx. ${ }^{2}$ Rabasa consideraba que el cuarto poder,
\end{abstract}

Fecha de recepción: 19 de febrero de 2017

Fecha de aceptación: 24 de julio de 2018

* La investigación de este trabajo se realizó con el apoyo de Ismael Jiménez Gómez y Erika González Flores. Agradezco a los dictaminadores anónimos por sus puntuales observaciones y correcciones.

1 Rabasa, La Constitución, p. 33.

2 Para una discusión del debate sobre las constituciones centralistas en el siglo XIX, véase Andrews, De Cádiz, pp. 74-79. 
el Supremo Poder Conservador instituido en las Siete Leyes, era la institución que más descalificaba la legitimidad constitucional de aquel código:

$[\mathrm{P}]$ orque si por sus preceptos, las provincias, el Parlamento y el Poder Judicial quedaban deprimidos y maltrechos, no salía más medrado el Ejecutivo que había de subordinarse a un llamado Poder Conservador, en donde se suponía investir algo de sobrehumano, intérprete infalible de la voluntad de la nación [...] Este tribunal de superhombres, impecables, desapasionados y de sabiduría absoluta, podía deponer presidentes, suspender congresos, anular leyes, destruir sentencias [...] y debía ser obedecido sin réplica ni demora, so pena de incurrir el rebelde en delito de lesa nación. ${ }^{3}$

La idea de las Siete Leyes como una Constitución despótica es una sombra larga en la historiografía, a pesar de que el jurista Manuel Herrera y Lasso advirtió en 1966 que la interpretación de Rabasa de las Siete Leyes tenía "deficiencias [...] por omisión, inexactitud y error”. Señalaba que la Constitución de 1836 no otorgaba poderes soberanos al Supremo Poder Conservador, pues dispuso que sus facultades solamente se podrían usar en caso de que lo solicitara uno de los tres poderes. Igualmente precisó que el objetivo de la institución era evitar que los poderes cometieran abusos, razón por el cual "la desastrada institución tuvo el mérito de ser el intento inicial de lo que en el léxico de hoy llamaríamos el control de la constitucionalidad", tal y como habían notado juristas como José María Gamboa antes de Rabasa. ${ }^{4}$ En su opinión, la Constitución de las Siete Leyes no representaba un cambio muy grande en relación con la Constitución de 1824, por lo que era más razonable entenderlo como una reforma de aquel código.

\footnotetext{
3 Rabasa, La Constitución, p. 33.

${ }^{4}$ Herrera y Lasso, "Centralismo y federalismo", p. 631.
} 
Decía: "el constitucionalismo centralista est[aba] vaciado en el molde federal, remodelado". ${ }^{5}$

En 1972, Alfonso Noriega publicó su libro El pensamiento conservador y el conservadurismo mexicano, que hasta el día de hoy ofrece el tratamiento más completo de la ideología política y el contenido de las Siete Leyes. El punto de partida del libro es la hipótesis de que los proyectos constitucionales del periodo centralista fueron expresiones de un pensamiento embrionario conservador y despótico.

[...] la evolución del pensamiento [se puede dividir] en tres etapas bien diferenciadas: liberalismo ilustrado y constitucionalismo oligárquico, con su obra maestra, las Siete Leyes de 1836, en primer lugar; el "despotismo constitucional" bajo la influencia de Santa Anna, realizado en la Constitución de 1843[.] ${ }^{6}$

Al referirse a la década de 1830 , Noriega precisa que lo que en México tradicionalmente se ha llamado conservadurismo se corresponde mejor con el liberalismo "ilustrado", una variante de dicha filosofía distinta a la versión que generalmente se asocia con la revolución francesa, con la soberanía popular y los derechos universales del hombre (el liberalismo "democrático").?

El estudio de las Siete Leyes que realizó 20 años más tarde Reynaldo Sordo Cedeño en El Congreso en la primera República centralista (1993) se montó sobre el trabajo de Noriega, aunque hace varias críticas importantes a sus ideas. Sordo Cedeño vincula el proyecto político de las Siete Leyes con el desarrollo del debate acerca de la reforma a la Constitución de 1824 durante la década de 1830 en el Congreso General. Identifica cuatro

${ }^{5}$ Herrera y Lasso, "Centralismo y federalismo", p. 627.

${ }^{6}$ Noriega, El pensamiento conservador, t.1, p. 173.

7 Noriega, Elpensamiento conservador, t.1, pp. 155-156. 
grupos políticos dentro del Congreso: los santanistas, quienes apoyaban a Antonio López de Santa Anna; los federalistas, que rechazaban la necesidad de reformar la Constitución; los moderados, quienes promovían la reforma, y los centralistas, que buscaban el reemplazo del código. Al contrastar las principales críticas que los congresistas lanzaban en contra de la carta federal con las propuestas constitucionales de la facción centralista, llegó a la conclusión “de que aun los más decididos centralistas, los que elaboraron el proyecto, estaban conscientes de que se debían evitar los extremos”. En este sentido, retoma a Manuel Herrera y Lasso para argumentar que "las Bases [constitucionales de 1835] de ninguna manera son la antítesis del Acta Constitutiva de 1824 ". ${ }^{8}$

De acuerdo con las aportaciones de Sordo Cedeño y de Noriega, las Siete Leyes deben entenderse como el primer texto constitucional de los oponentes a la Constitución Federal de 1824; un grupo que, si bien era liberal en la década de 1830, se transformaría en conservador para la de 1850. Esta asociación entre las Siete Leyes y el origen del conservadurismo explica el desdén historiográfico frente a la Constitución de 1836, constante desde la época de Rabasa. Los historiadores que estudian la trayectoria constitucional mexicana de la primera mitad del siglo siguen concentrándose en historiar los tres momentos federalistas (1824-1847-1857), sin reconocer la relevancia del constitucionalismo de la carta de $1836 .{ }^{9}$

En este artículo se cuestiona dicha inclinación historiográfica para demostrar que las Siete Leyes constituyeron un antecedente histórico, tanto para el pensamiento constitucionalista conservador como para el liberal. De esta manera, se propone reevaluar el

8 Sordo Cedeño, El Congreso, p. 196.

9 Los ejemplos más importantes para este estudio son: Arroyo García, La arquitectura, y Noriega Elío, El Congreso Constituyente. Ambos subrayan las aportaciones de los debates de 1842 para el constitucionalismo de $1847 \mathrm{y}$ 1857, pero dedican pocas páginas a las Sietes Leyes. 
legado de la Constitución de 1836. En otros textos, he subrayado los vínculos evidentes entre estas ideas y el debate en torno a la reforma a la Constitución de $1824 .{ }^{10}$ De modo que el objetivo aquí es seguir los vaivenes de las principales ideas presentes en la Constitución de 1836 en el debate constitucional mexicano posterior. No es mi intención hacer la historia pormenorizada de todas las constituciones y las reformas constitucionales a partir de 1836. Tal trabajo rebasa las posibilidades de este espacio. Quiero solo señalar los ecos de la Constitución de 1836 que he identificado en los textos políticos y constitucionales publicados después de su promulgación.

En consecuencia, se evaluará una variedad de documentos. Por un lado, están las constituciones -a saber, los códigos de 1824, 1836, 1843 y 1857- junto con el acta que reformó la Constitución de 1824 en 1847 (véase el cuadro 1) y las reformas constitucionales de 1874. Entre estos documentos también se encuentran las Bases Constitucionales de 1835 y el Acta Constitutiva de 1824, ambos textos partes integrales de las constituciones que antecedieron.

Por otro lado, están los proyectos de constitución y proyectos de reforma de constitución publicados entre 1835 y 1870 (y aquí incluyo proyectos que nunca llegaron a ser adoptados). Los más importantes para este estudio son los proyectos de reforma a la Constitución de 1836, así como los tres proyectos constitucionales que emitió la Comisión de Constitución del malogrado Congreso Constituyente de 1842 (véase el cuadro 2). Después de la publicación del Acta de Reforma de 1847, el Congreso General siguió discutiendo posibles reformas a la Constitución hasta 1852. De manera que se mencionarán también las propuestas de reforma constitucional de Teodosio Lares y Marcelino Castañeda, así como una propuesta para suprimir el Senado, provenientes de este periodo.

10 Andrews, "Discusiones en torno", y "El debate político”. 
Cuadro 1

CONSTITUCIONES Y TEXTOS CONSTITUCIONALES (1824-1865) ${ }^{11}$

\begin{tabular}{lcl}
\hline Texto & Año & Cuerpo deliberativo \\
\hline Acta Constitutiva & 1824 & Congreso Constituyente \\
Constitución Federal & 1824 & Congreso Constituyente \\
Bases Constitucionales & 1835 & Congreso Constituyente \\
Leyes Constitucionales & 1836 & Congreso Constituyente \\
Bases de Tacubaya & 1841 & Ejército de Operaciones \\
$\begin{array}{l}\text { Bases Orgánicas } \\
\text { Acta de Reforma a la Constitución }\end{array}$ & 1843 & Junta Nacional Legislativa \\
$\quad$ de 1824 & & Congreso Constituyente \\
$\begin{array}{l}\text { Bases para la administración de la } \\
\quad \text { República hasta la promulgación }\end{array}$ & 1853 & (Antonio López de Santa \\
$\quad$ de la Constitución & & Anna) \\
$\begin{array}{c}\text { Estatuto orgánico provisional } \\
\quad \text { de la República Mexicana }\end{array}$ & 1856 & (Ignacio Comonfort) \\
$\begin{array}{c}\text { Constitución Política de la } \\
\quad \text { República Mexicana }\end{array}$ & 1857 & Congreso Constituyente \\
$\begin{array}{c}\text { Estatuto Provisional del Imperio } \\
\quad \text { Mexicano }\end{array}$ & 1865 & Consejo del Estado \\
\hline
\end{tabular}

En tercer lugar, están los dictámenes acerca de estos proyectos realizados por varios ramos del gobierno. Entre 1840 y 1841, por ejemplo, casi todas las asambleas departamentales emitieron dictámenes acerca del proyecto de reforma de la Cámara de Diputados para la Constitución de $1836 .^{12}$ Por las fuentes, sé que el Consejo de Gobierno y la Suprema Corte de Justicia también elaboraron dictámenes del proyecto en el verano de 1841. He localizado una versión incompleta del dictamen del Consejo, pero no he topado rastro del dictamen de la Corte.

11 Las referencias completas a estos textos se encuentran en la bibliografía.

12 Sordo Cedeño analiza las discusiones del Congreso General respecto de la reforma y menciona algunos de los dictámenes de las juntas departamentales, véase Sordo Cedeño, El Congreso, pp. 394-404. 
Finalmente, están los discursos y publicaciones contemporáneas de los actores políticos involucrados en los debates. Los votos particulares de los congresistas miembros de las comisiones de Constitución son asimismo fuentes importantes para mi estudio. Hay que mencionar, sobre todo, el voto de Pedro Ramírez sobre el proyecto de reforma constitucional de 1840, así como el de Mariano Otero acerca del proyecto del Acta de Reforma en 1847 (véase el cuadro 2). ${ }^{13}$

Es claro que todas estas fuentes no gozan del mismo estatus jurídico ni tienen la misma importancia para el desarrollo de la historia constitucional. No obstante, todas son resultado del debate político que se realizaba en salas legislativas, comisiones y en las páginas de las publicaciones periódicas. Esta discusión en su conjunto compone el pensamiento constitucional decimonónico. Considerar que las constituciones y reformas constitucionales son las únicas fuentes de la historia constitucional es ignorar que ellas se desarrollaron en el contexto de un debate mucho más amplio. Así las cosas, y puesto que este artículo busca evaluar el legado de las Siete Leyes para el pensamiento constitucional decimonónico, es necesario examinar tanto las leyes constitucionales como las propuestas que no pasaron de tales.

Las ideas rectoras de las Siete Leyes que he identificado como transcendentes para el pensamiento constitucional mexicano son: la insistencia en la supremacía del gobierno general sobre los gobiernos de los departamentos, la introducción de

\footnotetext{
${ }^{13}$ En las colecciones de constituciones y fuentes primarias para el estudio de las constituciones, generalmente se atribuye este voto a José Fernando Ramírez. No obstante, éste no era diputado del segundo Congreso Constitucional de las Siete Leyes. Los diputados de apellido Ramírez eran Pedro Ramírez (para Zacatecas), Mariano Ramírez (para Chihuahua) y Manuel Ramírez (suplente para Jalisco). Véase Sordo CedeÑo, El Congreso, p. 444. José Luis Soberanes argumenta que el autor del voto era Pedro Ramírez. Véase Soberanes FERnÁndeZ, Historia, p. 207.
} 
requisitos para garantizar “el buen carácter” de los electos, y reformas al sistema electoral para garantizar la representación nacional en los poderes generales; la introducción de pesos y contrapesos para regular la división de poderes, la inclusión de una carta de derechos, y, finalmente, la creación de un mecanismo para promover el debido cumplimiento de la Constitución. A lo largo del ensayo se detallará cada una de estas características de las Siete Leyes y se demostrará su particularidad mediante la comparación con las previsiones de la Constitución Federal. Enseguida se analizará la trayectoria de estas características a partir de 1836, y se reflexionará acerca de la importancia (o no) de estas ideas para el debate constitucional posterior.

\section{Cuadro 2}

PROYECTOS DE CONSTITUCIÓN Y DE REFORMA CONSTITUCIONAL $(1840-1867)^{14}$

\begin{tabular}{lll}
\hline Texto & Año & Autor \\
\hline $\begin{array}{l}\text { Proyecto de reforma } \\
\text { constitucional }\end{array}$ & 1840 & $\begin{array}{l}\text { Comisión de Constitución de la } \\
\text { Cámara de Diputados (José } \\
\text { María Jiménez, Pedro Barajas, } \\
\text { Demetrio del Castillo, Alonso }\end{array}$ \\
$\begin{array}{l}\text { Voto particular del } \\
\text { diputado Pedro } \\
\text { Ramírez }\end{array}$ & 1840 & $\begin{array}{c}\text { Fernández y Pedro Ramírez) } \\
\text { Pedro Ramírez }\end{array}$ \\
\hline
\end{tabular}

${ }^{14}$ Las referencias completas a los textos que aparecen en colecciones de documentos publicados se encuentran en la bibliografía. La lista de proyectos se limita a los mencionados en este artículo, aunque hay varios más -sobre todo para el periodo de 1849 a 1853 - en materia del nombramiento de los magistrados de la Suprema Corte y en torno a la garantía constitucional de los derechos. La mayor parte de ellos se pueden consultar en el Archivo Histórico del Senado. Arroyo García identifica y discute cuatro proyectos de constitución provenientes de 1856 en La arquitectura, pp. 293-307. 
Cuadro 2

PROYECTOS DE CONSTITUCIÓN Y DE REFORMA (continúa)

\begin{tabular}{|c|c|c|}
\hline Texto & Año & Autor \\
\hline $\begin{array}{l}\text { Proyecto de la mayoría } \\
\text { de la comisión de } \\
\text { Constitución }\end{array}$ & 1842 & $\begin{array}{l}\text { Comisión de Constitución del } \\
\text { Congreso Constituyente } \\
\text { (Antonio Díaz Guzmán, } \\
\text { Joaquín Ladrón de Guevara, } \\
\text { Pedro Ramírez y José Fernando } \\
\text { Ramírez) }\end{array}$ \\
\hline $\begin{array}{l}\text { Proyecto de la minoría } \\
\text { de la comisión de } \\
\text { Constitución }\end{array}$ & 1842 & $\begin{array}{l}\text { Mariano Otero, Juan José Espinosa } \\
\text { de los Monteros y Octaviano } \\
\text { Muñoz Ledo }\end{array}$ \\
\hline $\begin{array}{l}\text { Segundo proyecto } \\
\text { de la comisión de } \\
\text { Constitución }\end{array}$ & 1842 & $\begin{array}{l}\text { Comisión de Constitución del } \\
\text { Congreso Constituyente }\end{array}$ \\
\hline $\begin{array}{l}\text { Proyecto de bases de } \\
\text { organización para la } \\
\text { República Mexicana }\end{array}$ & 1843 & $\begin{array}{l}\text { Comisión de Constitución de } \\
\text { la Junta Nacional Legislativa } \\
\text { (Sebastián Camacho, Cayetano } \\
\text { Ibarra, Manuel Baranda, Manuel } \\
\text { de la Peña y Peña y Simón de la } \\
\text { Garza) }\end{array}$ \\
\hline $\begin{array}{l}\text { Voto particular de } \\
\text { Mariano Otero y } \\
\text { proyecto del Acta de } \\
\text { Reforma }\end{array}$ & 1847 & Mariano Otero \\
\hline $\begin{array}{l}\text { Proyecto de reformas a la } \\
\text { Constitución }{ }^{\text {a }}\end{array}$ & 1850 & Anónimo (“Unos diputados”) \\
\hline $\begin{array}{l}\text { Proyecto de reformas } \\
\text { constitucionales } \\
\text { presentado a la Cámara } \\
\text { de Diputados }{ }^{b}\end{array}$ & 1851 & Marcelino Castañeda \\
\hline $\begin{array}{l}\text { Proyecto de reforma } \\
\text { constitucional } \\
\text { presentado a la Cámara } \\
\text { de Diputados }^{c}\end{array}$ & 1852 & Teodosio Lares \\
\hline
\end{tabular}

a Unos diputados, "Reformas a la constitución: Supresión del Senado”, El Monitor Republicano (25 nov. 1850), pp. 1-2.

b "Proyecto de reformas constitucionales presentado por el Sr. Castañeda. En 11 del presente [feb. 1851]", AGN, Gobernación, s/s 1851, c. 389, exp. 3, ff. 1-12.

c "Reformas constitucionales", El Universal (13 feb. 1852). 


\section{Cuadro 2}

PROYECTOS DE CONSTITUCIÓN Y DE REFORMA (concluye)

\begin{tabular}{|c|c|c|}
\hline Texto & $A \tilde{n} o$ & Autor \\
\hline $\begin{array}{l}\text { Proyecto de reforma } \\
\text { constitucional } \\
\text { presentado a la Cámara } \\
\text { de Diputados }{ }^{\mathrm{d}}\end{array}$ & 1852 & $\begin{array}{l}\text { Manuel Piña y Cuevas y el diputado } \\
\text { "Beduzco" }\end{array}$ \\
\hline $\begin{array}{l}\text { Proyecto de Constitución } \\
\text { política de la República } \\
\text { Mexicana }\end{array}$ & 1856 & $\begin{array}{l}\text { Comisión de Constitución del } \\
\text { Congreso Constituyente } \\
\text { (Ponciano Arrillaga, Mariano } \\
\text { Yáñez, León Guzmán, Pedro } \\
\text { Escudero y Echánove, José María } \\
\text { Castillo Velasco, José María } \\
\text { Cortés y Esparza, José María } \\
\text { Mata) }\end{array}$ \\
\hline Proyecto de Constitución ${ }^{\mathrm{e}}$ & 1856 & Mariano Arizcorreta \\
\hline $\begin{array}{l}\text { Estatuto Orgánico } \\
\text { Provisional de la } \\
\text { República }\end{array}$ & 1858 & $\begin{array}{l}\text { Consejo de Estado (Bernardo } \\
\text { Couto, presidente) }\end{array}$ \\
\hline $\begin{array}{l}\text { Iniciativa de reformas } \\
\text { constitucionales }\end{array}$ & 1867 & Sebastián Lerdo de Tejada \\
\hline
\end{tabular}

d El proyecto se leyó en la sesión de la Cámara de Diputados del 7 de mayo de 1852, reproducido en El Siglo XIX (3 jun. 1852). No hay registro de un diputado con el apellido Beduzco en la Cámara de Diputados del periodo 1852-1853. Tal vez se trata de un error de captura por parte de El Siglo XIX, y el segundo autor del proyecto es Rafael Berruecos, quien era diputado por Puebla. Véase Moreno VALLE, Catálogo, pp. 946-947.

e "Sesión secreta extraordinaria del 23 de junio de 1856", p. 288.

\section{LA SOBERANÍA NACIONAL Y LA SUPREMACÍA DEL GOBIERNO GENERAL}

El primer aspecto fundamental y determinante que distinguía al constitucionalismo centralista de su predecesor federal era la declaración de la soberanía nacional, expresada en el primer artículo de las Bases Constitucionales: "Art. 1. La Nación Mexicana, una, soberana e independiente, como hasta aquí, 
no profesa ni protege otra religión que la católica, apostólica, romana, ni tolera el ejercicio de otra alguna".

De acuerdo con las definiciones políticas aceptadas del momento, esta declaración establecía el "centralismo" del proyecto constitucional de 1836. En el debate político hasta el momento, solamente se admitía por federalismo una forma de gobierno que reconocía tanto la soberanía nacional como la estatal. El Acta Constitutiva de 1824 había declarado, por esta razón, que la soberanía residía en la nación, y que los estados eran soberanos "en lo que exclusivamente toque a su administración y gobierno interior" ${ }^{15}$ La Constitución Federal no hizo mención del tema, por lo que el significado de la soberanía estatal se debatió durante la primera república, pero sí insistió en la primacía del gobierno general sobre los estados. Exigió que éstos organizaran "su gobierno y administración interior sin oponerse a esta Constitución ni a la acta constitutiva”, y señaló que sus gobiernos deberían guardar y hacer "guardar la constitución y leyes generales de la Unión” (art. 161, incisos I e III). Igualmente, la carta de 1824 otorgó al Congreso general la prerrogativa de controlar centralmente la recaudación fiscal. El artículo 50, inciso 50, indicaba que era facultad exclusiva del Congreso General "fijar los gastos generales, establecer las contribuciones necesarias para cubrirlos [y] arreglar su recaudación”. ${ }^{16}$

No obstante, durante la primera república federal los estados rechazaron que sus gobiernos se subordinaran al gobierno general. Los debates en torno a los impuestos develaron esta hostilidad de manera clara. De hecho, los acuerdos entre el gobierno general y los estados en relación con el tema hacendario descansaron sobre el reconocimiento del gobierno general de que la facultad de imponer y recaudar impuestos a la población

15 “Acta Constitutiva de la Federación”, pp. 309-315. Para más detalles sobre esta cuestión, véase ANDREws, "La Constitución."

16 "Constitución federal," pp. 335-361. 
se reservaba exclusivamente para los estados. Por esta razón, y porque la exhortación a que los gobiernos de los estados respetaran las leyes generales de la República y la Constitución no garantizaba en absoluto su cumplimiento, la primera república federal se caracteriza como un periodo confederal. ${ }^{17}$

La declaración de soberanía nacional en 1835 permitió que las Siete Leyes establecieran una forma de gobierno en la cual el gobierno general sería el único representante de la soberanía. Gracias a ella, la primera ley pudo declarar los derechos del mexicano (mientras que durante la República Federal, las constituciones estatales se habían encargado de este asunto). El anunciado también respaldó la pretensión de que el poder conservador pudiera garantizar el cumplimiento de la Constitución por igual en todo el territorio de la República. Finalmente -el tema que interesa en este apartado- la declaración de la soberanía nacional única dio pie al establecimiento, en la cuarta ley, de una clara jerarquía entre el gobierno general y los estados, ahora llamados departamentos.

La quinta ley, entonces, estableció cómo cada departamento debería organizar y elegir su gobierno interno, y subrayó su subordinación al gobierno general. El presidente escogería al gobernador de departamento ( $4^{\mathrm{a}}$ ley, art. 17, inciso 11), mientras que el Congreso General gozaría de la facultad de "aprobar, reprobar o reformar las disposiciones legislativas" que dictaran las juntas departamentales ( $3^{\text {a }}$ ley, art. 44, inciso 2). Esto no significaba que la distribución de facultades entre el gobierno general y los gobiernos departamentales crearía un sistema centralista en que los departamentos se redujeran a meros cuerpos administrativos dependientes del gobierno general. Las Siete Leyes conservaron un elemento característico del constitucionalismo anterior con la creación de juntas departamentales electas por la ciudadanía que serían el órgano representativo de

17 Andrews, De Cádiz, pp. 121-126. 
su departamento frente al gobierno general. En el caso de la elección de gobernador del departamento, las juntas departamentales propondrían la terna al gobierno general ( 6 a ley, art. 14 , inciso 12) y votarían en nombre de los departamentos en las elecciones para la Presidencia de la República, y senadores y magistrados de la Suprema Corte de Justicia (6 ${ }^{\mathrm{a}}$ ley, art. 14 inciso 11$) .{ }^{18} \mathrm{La}$

18 Israel Arroyo García sostiene que la redacción de las Siete Leyes no dejaba claro el modo de elección para presidente. Argumenta que hay una confusión en el texto entre "juntas de departamento" y "juntas de electores de departamento" y señala que las convocatorias reglamentarias del 30 de noviembre y 24 de diciembre de 1836 nos demuestran que el cuerpo encargado de elegir eran las juntas electorales de departamento. Arroyo García, "La arquitectura de la república”, p. 97. No obstante, se trata de un error de comprensión de su parte, pues tanto la Constitución como las convocatorias son muy claras al respecto. La segunda ley indica en el art. 2 que las juntas departamentales votarían en la elección a presidente a partir de una terna que se le entregaría a la Cámara de Diputados. En la sexta ley, artículo 14, inciso XI se estipula que les toca a las juntas departamentales: "Hacer las elecciones del Presidente de la República, miembros del Supremo Poder Conservador, senadores e individuos de la Suprema Corte de Justicia y Marcial, según está prevenido en las respectivas leyes constitucionales”. En cuanto a las convocatorias, la del 30 de noviembre establece el procedimiento para elegir la junta departamental y los diputados a la Cámara de Diputados de cada departamento. Como era costumbre en el siglo xix, se trataba de una elección de tres niveles: en el primero (de municipio) los ciudadanos escogían electores compromisarios; aquellos se reunían en la capital del partido con sus compañeros compromisarios de los demás municipios de la jurisdicción para elegir los electores de partido; finalmente, los electores de partido se reunían en la capital del departamento para nombrar los electos a la Junta Departamental y a la Cámara de Diputados. La convocatoria del 24 de diciembre establece el horario de estas últimas elecciones. El art. 3 establece que "se reunirán los electores de partido en la capital de su Departamento para verificar el 14 y 15 [de marzo] la elección de diputados al congreso nacional y a la junta departamental”. El art. 4 prosigue: "A los electos para dichas juntas [es decir, las departamentales mencionadas en el artículo anterior] se les comunicará por medio del gobernador respectivo y por extraordinario su nombramiento"; y añade, "no podrán excusar de concurrir a la instalación de ellas y verificar los actos que exige el artículo 6 de esta ley”. Según el art. 5 la instalación de las juntas departamentales debería ser el 26 de marzo. Los actos que exige el art. 6 que realicen los diputados después 
diferencia con la Constitución de 1824 en este punto era que durante la República Federal las legislaturas estatales votaron libremente para candidatos a estas posiciones. En la república de las Siete Leyes, los poderes de gobierno integrarían listas y ternas para los cargos a senadores y presidente y las juntas votarían con base en aquellas listas. Asimismo, aunque las asambleas no tendrían facultades legislativas, el artículo 14 de la séptima ley constitucional las dotó de prerrogativas para iniciar leyes ante el Congreso General "relativas a impuestos, educación pública, industria, comercio, administración municipal y variaciones constitucionales"; de supervisar las cuentas públicas del departamento, y de elaborar las disposiciones y reglamentos necesarios para "la conservación y mejora de los establecimientos de instrucción y beneficencia pública, y las que se dirijan al fomento de la agricultura, industria y comercio".

Al margen de estas aclaraciones, es indudable que la declaración inequívoca de la soberanía y la consecuente jerarquización clara en la relación entre el gobierno general y los gobiernos departamentales fue un momento decisivo para el desarrollo del constitucionalismo en México. Todos los proyectos constitucionales discutidos en México durante la década de 1840 buscaban dar facultades al gobierno general para que pudiera frenar la actuación legislativa de los gobiernos de los estados o departamentos. Todos, incluso cuando reconocían la soberanía estatal, como en el caso del Acta de Reforma de 1847, claramente subordinaban los gobiernos estatales al nacional en materia legislativa. La diferencia entre los proyectos claramente centralistas, como las Bases Orgánicas, y las propuestas de índole federal era el tipo de facultad legislativa que cada uno otorgaba a los estados/departamentos.

de instalarse son: "la elección de presidente de la República: al inmediato la de senadores; y el día siguiente la de los individuos a la corte Marcial”. Véase Dublán y Lozano, La legislación, vol. 3, pp. 215-222 y 226-227. 
De esta manera, el proyecto de la minoría de la Comisión de Constitución de 1842 y el segundo proyecto de la misma, ambos generosos con las prerrogativas otorgadas a los departamentos al permitir el manejo autónomo de sus finanzas y de la administración de justicia, ${ }^{19}$ indican con firmeza que los gobiernos locales deberían entenderse como instancias subordinadas a la Constitución nacional. ${ }^{20} \mathrm{El}$ segundo proyecto de la comisión otorgaba a los gobernadores de departamento la facultad de suspender las leyes emitidas por las asambleas departamentales si no cumplían con la Constitución (art. 107). Esta suspensión debería ser avalada enseguida por el Senado (art. 141). ${ }^{21}$ El Acta de Reforma de 1847, que restituyó la Constitución de 1824 y con ella la facultad legislativa amplia a los gobiernos, incluyó un artículo que daba al Congreso General la prerrogativa expresa de anular las leyes de los estados (Acta, art. 141).

\section{ELECCIONES Y REPRESENTACIÓN}

Otra diferencia entre las Siete Leyes y la Constitución Federal de 1824 es la manera en que organizaron el sistema electoral. En cuanto a las elecciones populares a la Cámara de Diputados, las leyes constitucionales introdujeron requisitos censitarios para votar y ser votado. La Constitución Federal y las constituciones estatales permitían el voto universal masculino (con excepciones de tipo moral) en las elecciones populares y en ningún tipo de elección exigían requisitos censitarios a los

\footnotetext{
19 Noriega Elío, El Congreso Constituyente, pp. 99, 157-158.

20 Dice Israel Arroyo: “En resumen, resalta la convergencia de ambos grupos [federalistas y centralistas] en posturas que tendían a fortalecer los poderes centrales frente al desbordamiento vivido en el periodo confederalista de 1824-1835 y, al mismo tiempo, el debilitamiento de los excesos unitarios de 1835-1841. No se debe escatimar al Constituyente de 1842 su originalidad en cuanto a desvanecer el horizonte confederalista y anteponer un republicanismo federal". Arroyo García, La arquitectura, p. 203.

21 Noriega Elío, El Congreso Constituyente, pp. 161 y 173.
} 
candidatos. Además, dio plena libertad a las juntas electorales (en sus diferentes etapas y formas) para realizar la selección de candidatos. La Constitución de 1836, en cambio, estableció un ingreso mínimo de 100 pesos para alcanzar la ciudadanía política, e impuso mínimos de ingreso diferenciados para ser votado a los diferentes cargos de elección.

Asimismo, las leyes constitucionales de 1836 admitían la selección independiente de candidatos únicamente para las elecciones a la Cámara de Diputados. En el caso de las elecciones al Senado, la Cámara de Diputados, el gobierno y la Suprema Corte de Justicia se elaboraría una lista de 24 nombres. Las juntas departamentales votarían por sus senadores a partir de esta lista. En el caso de la Presidencia, el presidente en ejercicio (con el acuerdo del Consejo), el Senado y la Suprema Corte integrarían ternas de candidatos, quienes deberían tener un ingreso mínimo de 4000 pesos y haber desempeñado un cargo civil o militar alto (4a ley, art. 14, incisos III y IV). La Cámara de Diputados discutiría las ternas para luego votar una nueva y circularla entre las juntas departamentales. Las juntas escogían un candidato con base en la terna de la cámara. Finalmente, en el caso del Supremo Poder Conservador, el proceso era el inverso: en primer lugar, las juntas departamentales remitirían sus recomendaciones para el o los cargos a llenar, y la Cámara de Diputados discutiría los candidatos seleccionados e integraría una terna con base en los nombres remitidos. Esta terna se pasaría al Senado, que realizaría la elección del nuevo miembro del Poder Conservador. Para ser miembro del Poder Conservador se requería un ingreso anual mínimo de 3000 pesos y haber sido presidente o vicepresidente de la República, senador, diputado o secretario de despacho o ministro de la Suprema Corte de Justicia ( $2^{\mathrm{a}}$ ley, art. 11, incisos II y III).

La insistencia en cuidar el perfil del electo a cargo público fue característica de todo el periodo centralista. Los constituyentes de 1842 propusieron mantener un requisito de ingreso mínimo 
a los senadores y diputados, por ejemplo. El primer proyecto de la comisión estableció un requisito de renta mínima de 1200 pesos para ser diputado (art. 51), pero permitía la candidatura de los profesores de ciencia que no cumplían con el requisito. Para ser senador fijó un ingreso mínimo de entre 2000 y 3000 pesos, experiencia previa en algún cargo de gobierno ("presidente de la república, secretario del despacho del supremo gobierno, o individuo del extinguido consejo constitucional, senador al congreso general, ministro o agente diplomático, o gobernador constitucional de departamento. Ejercer o haber ejercido alguno de los siguientes cargos: diputado al congreso nacional, o algún empleo superior y efectivo de la milicia”, art. 54) y tener una propiedad de bienes raíces. ${ }^{22}$

El proyecto de la minoría establecía un ingreso mínimo de 3000 pesos para los aspirantes a senador y 1200 para diputado. El segundo proyecto de la comisión, por su parte, estipulaba los mismos requisitos de ingreso mínimo. Pero establecía que los candidatos al Senado que habían ocupado previamente un cargo dentro de los tres poderes de gobierno o habían sido general de

${ }^{22}$ El primer proyecto establecía requisitos diferenciados para los distintos tipos de ingreso o renta. El art. 54 reza: "Para ser senador se requiere: 1 . Ser mexicano por nacimiento y natural o vecino del departamento que lo elige; 2 . Tener 35 años cumplidos de edad al tiempo de la elección; 3 . Haber ejercido alguno de los cargos siguientes: presidente de la república, secretario del despacho del supremo gobierno, o individuo del extinguido consejo constitucional, senador al congreso general, ministro o agente diplomático, o gobernador constitucional de Departamento. Ejercer o haber ejercido alguno de los siguientes: diputado al congreso nacional, o algún empleo superior y efectivo de la milicia. 4. Tener un capital propio consistente en bienes raíces o en un establecimiento industrial que produzca al nombrado una renta efectiva de dos mil pesos, o bien una industria o profesión que le produzca la misma renta, y además una propiedad territorial que valga 12000 pesos. Los individuos cuyo capital moral consista en los proventos de un empleo, comisión o beneficio eclesiástico, deben tener una renta de 3000 pesos y una propiedad territorial que valga 20000 libres". 
brigada o división no necesitarían más renta que la estipulada para diputados (1200 pesos anuales).

En las Bases Orgánicas, se pedía que los diputados comprobaran ingresos de 1200 pesos y que los senadores tuvieran 2000 pesos o bien una propiedad raíz con valor de 40000 pesos o más. En esta Constitución, además, se señalaba que el Senado se compondría de 63 senadores, 42 electos por las asambleas departamentales y 21 electos por el mismo Senado a partir de listas integradas por la Cámara de Diputados, la Suprema Corte y el poder ejecutivo. Los candidatos al Senado electos por las asambleas serían de dos perfiles distintos: representantes de "clases" específicas, a saber, "agricultores, mineros, propietarios o comerciantes, y fabricantes” (art. 40). Los electos por parte de la Cámara, la Corte o el Ejecutivo deben ser personas "que se hayan distinguido por sus servicios y méritos en la carrera civil, militar y eclesiástica" (art. 39). Es decir, hombres con experiencia previa en el gobierno general o estatal (presidente o vicepresidente de la República, secretario de despacho, ministro plenipotenciario, senador o diputado al Congreso, consejero de gobierno, gobernador de estado o departamento). Los obispos y generales de división también podrían ser candidatos (art. 40).

Después del fin de las Bases Orgánicas, la convocatoria a las elecciones al Congreso Extraordinario de 1846 retomó la idea de elegir los representantes con base en "clases" y "experiencia”. Igualmente conservó la práctica de imponer requisitos censitarios. ${ }^{23}$ Como bien demuestra José Antonio Aguilar Rivera, el sistema electoral adoptado en la convocatoria de 1846 contemplaba elecciones de tipo corporativo en las que sólo podrían votar y ser votado los miembros de las clases indicadas. El método de elección variaba entre las elecciones de las diferentes clases. En algunas -como el caso de los mineros y los literatos- las

23 “Convocatoria”, El Monitor Constitucional (28 ene. 1846), pp. 1-3. 
elecciones fueron directas. En otras, como las de propietarios, comerciantes y manufactureros, fueron indirectas. ${ }^{24}$

Con el Acta de Reforma de 1847, se volvieron a imponer las reglas y requisitos para la elección a los poderes de gobierno establecidos en la Constitución Federal. No obstante, la legacía de los debates centralistas pesaba en las reformas que introdujo el Acta acerca de la elección y composición del Senado. El artículo 8 del Acta estipulaba que el Senado se expandiría para incluir dos senadores por estado (electos por sus legislaturas) y el mismo número de senadores electos por la Suprema Corte de Justicia y Cámara de Diputados (que en este caso, votaba por diputaciones) a partir de una lista elaborada por el propio Senado. ${ }^{25} \mathrm{El}$ artículo 10 insistía en que los senadores al Congreso General deberían tener experiencia previa como gobernantes a nivel nacional o estatal, miembro del poder legislativo general, miembros de la Suprema Corte de Justicia, haber sido jueces o magistrados (durante seis años), enviados diplomáticos (durante cinco años), jefes de hacienda o generales militares.

Precisamente fueron estas reformas las que generaban descontento entre los liberales puros en los primeros años de la década de 1850. En noviembre de 1850 los primeros proyectos para desaparecer al Senado circulaban con el argumento de que el Senado del Acta de Reforma era aristocrático y antiliberal. ${ }^{26}$ En 1852, los diputados Manuel Piña y Cuevas y Rafael Berruecos propusieron restablecer la elección de los senadores bajo las mismas condiciones de la versión original de la Constitución

\footnotetext{
${ }^{24}$ Aguilar Rivera, “La convocatoria,” pp. 537-541.

25 Para una discusión de la práctica del Congreso General de votar por estados o por diputaciones, véase ARroYo GARCÍA, La arquitectura, pp. 397-524

${ }_{26}$ Véase Unos diputados, "Reformas a la constitución", pp. 1-2. Posteriormente El Monitor Republicano publicó tres editoriales en torno a la conveniencia de suprimir el Senado (30 nov., 2 y 4 dic. 1850).
} 
de 1824. ${ }^{27}$ Este mismo sentimiento llevó a los constituyentes de 1857 a establecer un poder legislativo unicameral. Es más, cuando el Senado fue reintroducido al poder legislativo en 1874, el modelo adoptado era la Cámara de Senadores original de la Constitución de 1824 y no el Senado del Acta de Reforma. ${ }^{28}$

A pesar de la importancia de los cambios al sistema de representación y de elecciones inaugurados por las Siete Leyes, es importante insistir en que también se puede identificar una clara continuidad entre el código de 1836 y su antecesor. La carta federal encargaba a las legislaturas de los estados la facultad para ser el poder electoral para el Senado, la Presidencia y la Vicepresidencia, así como para los magistrados de la Suprema Corte. $\mathrm{Al}$ igual que las Siete Leyes, la única institución del Gobierno General electo por voto popular era la Cámara de Diputados. En este sentido, la Constitución de 1836 preservaba una parte fundamental del arreglo federal de 1824.

En los proyectos constitucionales de 1842 y 1843 la política mexicana abrazó la idea del gobierno representativo de una nación de ciudadanos. ${ }^{29}$ Entonces, tanto unos como otros quitaron la representación electoral a las asambleas departamentales en las elecciones al gobierno general. Los tres pro-

${ }^{27}$ Iniciativa leída en la sesión de la Cámara de Diputados del 7 de mayo de 1852, reproducido en El Siglo XIX (3 jun. 1852).

28 “Nov. 13 de 1874, núm. 7311”, en Derechos del pueblo mexicano, disco 1, sección 2, pp. 10-16. El Senado empezó a funcionar en septiembre de 1875, cuando adoptó el reglamento expedido en 1825 para la Cámara de Senadores de la Constitución Federal de 1824. En 1897 el Senado adoptó un nuevo reglamento. Véase, Limón EnRíquez, "El Senado como poder moderador," pp. 58-60. Tanto mi investigación como la de Limón Enríquez muestran las similitudes entre los senados de 1824 y 1874 y, por ende, ponen en tela de juicio la afirmación de María Luna de que el Senado de 1874 era "de una naturaleza distinta de la que había tenido en la historia mexicana”. Luna, El Congreso, p. 208.

${ }_{29}$ A pesar de que, como señala Israel Arroyo, la representación nacional había sido reconocida como principio en el artículo 5 de las Bases Constitucionales de 1835. Arroyo García, La arquitectura, p. 161. 
yectos constitucionales de 1842, así como las Bases Orgánicas, proponían otorgar en cambio el poder electoral para la elección del presidente y senadores a las juntas electorales de los departamentos. Aquellos cuerpos eran cuerpos electorales de segundo grado, electos por electores de distrito, quienes a su vez habían sido electos previamente por elección popular directa en las circunscripciones del departamento. En los proyectos federales y en las Bases Orgánicas se imaginaba que los colegios formaban un poder electoral continuo, pero periódicamente renovable, que elegiría a todos los cargos de elección popular en el gobierno general. ${ }^{30}$ No está de más señalar -como paréntesis- que este método de elección, que otorgaba una base popular representativa a los poderes legislativo y ejecutivo por igual, es sustancialmente el mismo que adoptó la Constitución de la República en $1857 .{ }^{31}$

\section{MODERAR LA DIVISIÓN DE PODERES}

La división de poderes que estableció la Constitución de 1836 representa un tercer elemento de ruptura entre este código y la Constitución Federal de 1824. Los críticos de la carta federal en 1830 insistieron en que la debilidad fundamental de la

\footnotetext{
30 "Segundo proyecto de constitución”, arts. 16-30; Bases Orgánicas, arts. 147-174.

${ }^{31}$ La diferencia principal entre la organización de elecciones al poder legislativo y al ejecutivo durante el periodo de las Bases Orgánicas y el de la Constitución de 1857 es de grado. La Constitución de 1857 redujo la elección indirecta a un solo grado. Asimismo, hay que recordar que la Constitución de 1857 estipulaba que los magistrados de la Suprema Corte también deberían ser electos popularmente. Es interesante notar que el artículo 18 del Acta de Reforma en 1847 presentaba una alternativa distinta al poder electoral. Este artículo prometía que mediante "leyes generales se arreglarán las elecciones de diputados, senadores, presidente de la República y ministros de la suprema corte de justicia”, y sugirió que para esto el Congreso podía hasta "adoptar [...] la elección directa".
} 
arquitectura constitucional de 1824 era la ausencia de pesos y contrapesos para frenar las usurpaciones de un poder sobre el otro. Como bien expuso Francisco Manuel Sánchez de Tagle, uno de los autores más importantes de las Siete Leyes, el problema principal se encontraba en la colusión entre el legislativo y el ejecutivo para desviar la constitucionalidad:

De aquí es que los poderes legislativo y ejecutivo, muchas veces con buena intención, muchas seducidos de la que se llama imperiosa ley de la necesidad [sic], se coluden cuando les parece que hay peligro común, y entonces se ayudan mutuamente para salir de la órbita de sus atribuciones, atacar impunemente los del judicial y hollar la constitución sin escrúpulo. ${ }^{32}$

Las Siete Leyes integraron a las tercera y cuarta leyes constituciones las pocas facultades que la Constitución de 1824 había otorgado al presidente y al Congreso General para frenarse mutuamente: a saber, el veto presidencial suspensivo sobre los proyectos de ley (1824, art. 56; 1826, $3^{\mathrm{a}}$ ley, art. 37) y el visto bueno que debía dar la Cámara de Senadores a los nombramientos presidenciales (1824, art. 110, inciso VI; 1835, 4 ley, art. 17, inciso 13). ${ }^{33}$ La tercera y cuarta leyes introdujeron nuevos pesos y contrapesos a la actuación de los poderes legislativo y ejecutivo. La segunda ley instauró un cuarto poder cuyo principal objetivo era frenar los actos inconstitucionales de los tres poderes tradicionales y preservar el régimen constitucional. Aquí se discutirá la relevancia de este poder en la cuestión de los pesos y contrapesos; en otro apartado se analizarán sus otras funciones.

La tercera ley constitucional conservaba la naturaleza bicameral del Congreso General. Sin embargo, la Constitución

\footnotetext{
32 Sánchez de Tagle, Discurso del Sr. D. Francisco Tagle, pp. 9-10.

33 Aquí la única modificación introducida por la cuarta ley era la que estipuló que, para nombramientos a las oficinas de Hacienda, el presidente debía tener el visto bueno de la Cámara de Diputados en lugar del Senado.
} 
de 1836 no instauró dos cámaras colegislativas a la manera de 1824, sino que estableció una cámara de iniciativa y otra revisora. Es decir, los proyectos de ley podrían iniciarse en cualquiera de las cámaras durante la república federal, pero las Siete Leyes estipularon que todos los proyectos de ley debían empezarse en la Cámara Baja sin excepción ( $3^{a}$ ley, art. 55). Una vez que el proyecto recibiera sanción por parte de los diputados, pasaría al Senado, en donde los senadores aprobarían o rechazarían el proyecto (art. 57). Si los senadores acordaban enmendar o hacer adiciones al proyecto, se regresaría a la Cámara de Diputados, donde se introduciría la limitante (no presente en 1824) de que los representantes volvieran a debatir únicamente las enmiendas o adiciones (art. 61). Los proyectos de ley regresados requerirían de una mayoría de dos tercios (y no la mayoría absoluta estipulada en el art. 55 de la Constitución de 1824) en la Cámara de Diputados para volverse a presentar al Senado. Sería necesaria la misma mayoría para frenar la iniciativa nuevamente ( $3^{\mathrm{a}}$ ley, art. 58$)$.

De este modo, el Senado debería actuar como un contrapeso efectivo ante la Cámara de Diputados. Esta idea también se reflejaba en los cambios al escrutinio de los resultados de las elecciones. La Constitución de 1824 establecía que cada cámara se encargaría de la calificación de las elecciones (art. 35). En cambio, la tercera ley constitucional estipulaba que el Senado calificaría las elecciones a la Cámara de Diputados (art. 5), mientras que el Supremo Poder Conservador calificaría los comicios del Senado (art. 8). La supervisión de una cámara ajena quitaba a los congresistas la autonomía de que habían gozado para el escrutinio electoral, y debería servir de contrapeso para evitar cualquier irregularidad.

Las otras innovaciones de las Siete Leyes en materia de los contrapesos al poder legislativo se encontraban en la facultad que la cuarta ley otorgaba al poder ejecutivo para mandar sus representantes a las cámaras con el fin de "manif[estar] y 
apoy[ar] la opinión del gobierno" (4 ${ }^{\mathrm{a}}$ ley, art. 15, inciso VII) y la facultad que tenía el Supremo Poder Conservador para suspender las sesiones de las cámaras hasta por tres meses ( $2^{\mathrm{a}}$ ley, art. 12, inciso 4). Hay que decir que los representantes ejecutivos solían ser los ministros de despacho y el motivo de su participación en los debates parlamentarios era -desde luego- intentar guiar a los legisladores hacia una decisión conveniente a los deseos del poder ejecutivo.

Los proyectos constitucionales de 1842, así como las Bases Orgánicas, conservaron la mayor parte de los pesos y contrapesos provenientes de las Siete Leyes en sus diseños del poder legislativo. En los cuatro textos, el Senado se concebía únicamente como una institución de revisión y no se le otorgaba la facultad de iniciar legislación. Todos los proyectos de 1842 incluían unas previsiones que buscaban proteger el proceso electoral de la interferencia de los actores políticos: el segundo proyecto de la comisión señalaba que "[e]l poder electoral en todos sus grados es independiente de todo otro poder político, y a él sólo pertenece la calificación y revisión de todos sus actos” (art. 22). Encargaba el escrutinio electoral final de los candidatos al Senado y a la Cámara de Diputados de manera conjunta (art. 27). Aunque las Bases Orgánicas permitieron a la Cámara de Diputados y al Senado calificar sus propias elecciones, los constituyentes de 1843 copiaron casi textualmente el artículo 27 del segundo proyecto en el artículo 153.

La facultad constitucional para que los representantes del gobierno pudieran participar en los debates del Congreso General, contemplada en el artículo 15 de la cuarta ley de 1836, también perduró en la historia constitucional. La convocatoria a elecciones al Congreso Constituyente en 1841 señalaba que el poder ejecutivo podría participar en los debates en torno al proyecto de Constitución. Durante los debates iniciales en torno al reglamento del Congreso Constituyente de 1842, el gobierno de Antonio López de Santa Anna insistió en que los constituyentes 
también permitieran la participación de los ministros de gobierno en todos los debates "tanto en público como en secreto". 34 Aunque los constituyentes accedieron, omitieron incluir un artículo en ese sentido en los proyectos de la constitución de 1842. La Junta Nacional Legislativa de 1843, en cambio, sí insertó una fracción al artículo 87 de las Bases Orgánicas, en la cual se permitía al presidente "[n]ombrar oradores del seno del Consejo [de Gobierno], que concurran a las cámaras cuando lo estimare conveniente, para manifestar o defender las opiniones del Gobierno". La participación de los ministros en el debate del Congreso continuaba hasta el Congreso Constituyente de 1857 en donde, asimismo, varios miembros del gobierno de Comonfort también ocupaban curules en el Congreso. ${ }^{35}$

La cuarta ley adoptó el mismo principio de pesos y contrapesos adicionales para el poder ejecutivo. Los constituyentes de 1836 eliminaron el cargo de vicepresidente para erigir un ejecutivo unipersonal, pero no dotaron al presidente de autonomía frente a los demás poderes. El presidente fungiría como jefe del poder ejecutivo, pero ejercería sus funciones bajo la permanente vigilancia y supervisión de un Consejo de Gobierno. Este consejo se formaría de trece miembros vitalicios, con al menos dos militares y dos eclesiásticos. Los miembros deberían ser nombrados por el presidente a partir de una terna elaborada por el Senado (art. 21). El Consejo se asemejaba al Consejo de Estado de la Constitución de 1812, pero tenía funciones más amplias para frenar el actuar presidencial. En particular, el presidente debería buscar el acuerdo del Consejo antes de ejercer muchas de sus facultades más importantes: presentar un proyecto de ley, nombrar a los gobernadores a partir de las ternas de las juntas departamentales, excitar al Supremo Poder

${ }^{34}$ Noriega Elío, El Congreso Constituyente, p. 89.

35 David Pantoja Morán discute los elementos parlamentarios del Congreso Constituyente y del Congreso General durante la República Restaurada en “La Constitución de 1857”; véanse especialmente pp. 1057, 1061-1062. 
Conservador y conceder el indulto. El contrapeso más importante que ostentaba el presidente ante el Congreso -el derecho a un veto suspensivo en una sola ocasión- también requería el acuerdo del Consejo de Gobierno (art. 17). ${ }^{36}$

Finalmente, el contrapeso externo más importante a la acción del Poder Ejecutivo provendría del Supremo Poder Conservador, que podría decidir -por excitación del Congreso General"la incapacidad física o moral del presidente" ( $2^{\mathrm{a}}$ ley, art. 12, inciso IV), o bien -por excitación de la mayoría de las juntas de departamento- cuando estuviera "el presidente [...] en el caso de renovar todo el ministerio por bien de la nación” (art. 12, inciso IX). La primera atribución la había ejercido el Congreso General en 1830 para remover a Vicente Guerrero de la presidencia, aunque la facultad expresa no aparecía en la Constitución de $1824 .{ }^{37}$ La segunda era una innovación de los constituyentes de 1836 y reflejaba que una de las principales demandas de los pronunciamientos del periodo era la remoción del ministerio. ${ }^{38}$

El Consejo de Gobierno de 1836 prosperó de varias maneras en los proyectos constitucionales del periodo centralista: el cuerpo reapareció en los proyectos de Constitución de 1842 y las Bases Orgánicas de 1843. En los proyectos de 1842 se replanteó al Consejo como "los secretarios del despacho en junta", pero mantuvo la obligatoriedad de sus opiniones como contrapeso para el actuar presidencial establecido en 1836. Los tres proyectos estipulaban que el presidente buscara el acuerdo del Consejo antes de hacer uso del veto suspensivo. El Consejo de Gobierno de las Bases Orgánicas, en cambio, conservó el Consejo como un comité adicional del poder ejecutivo, pero a su vez lo subordinó al presidente. En el artículo 104 señalaba que

\footnotetext{
36 Para la historia de los antecedentes de este Consejo, véase AndREws, "Moderation vs. Conservation.”

37 Al respecto véase ANDREws, Entre la espada, pp. 143-144.

38 Fowler, Independent Mexico.
} 
el Consejo debe consistir en 17 consejeros vitalicios nombrados por el presidente. En contraste con 1836, al presidente no se le exigía hacer su elección con base en ninguna terna. El artículo 87 señalaba que el presidente debería ejercer su veto suspensivo o dar pase a las comunicaciones papales (incisos XIX y XX) "con audiencia del Consejo", pero sin la obligación de tomar en cuenta su parecer.

Asimismo, diversos Consejos de Gobierno operaron durante los gobiernos conservadores posteriores. Teodosio Lares fue el autor intelectual de las leyes que regían los Consejos durante la dictadura de Santa Anna (1853-1855) y el Segundo Imperio (1863-1866). ${ }^{39}$ Además de concebir el Consejo como un cuerpo consultativo al servicio del presidente, al estilo de las Bases Orgánicas, Lares favoreció asimismo otorgarle la facultad de decidir las cuestiones contencioso-administrativas, a la manera de los Consejos de Estado en Francia. ${ }^{40}$ Lares presentó por primera vez un proyecto de esta naturaleza en febrero de 1852 con el fin de reformar la Constitución de 1824 y el Acta de Reforma de $1847 .{ }^{41}$ Sugirió que la Cámara de Diputados elabo-

39 Véase el título Consejo de Estado en "Bases para la administración de la República”, arts. 1-4, p. 437; “Consejo de Estado. Se establece uno y se marca sus atribuciones” (4 dic. 1864), en Leyes, decretos, circulares y providencias, t. 3, p. 231.

40 LAREs, "Ley para el arreglo de lo contencioso administrativo", (25 mayo 1853); y "Ley sobre lo contencioso administrativo" (1o nov. 1865).

41 "Reformas constitucionales", El Universal (13 feb.1852). Hay que señalar, sin embargo, que el futuro presidente de la Suprema Corte, Marcelino Castañeda, presentó al Congreso General, en su calidad de senador, un proyecto para añadir un Consejo de Estado a la Constitución Federal en 1851, un año antes del proyecto de ley de Lares. Este proyecto quería que el Consejo tuviera el "carácter de tribunal, tenga el ejercicio de funciones judiciales, no para dar y quitar derechos, sino para decidir contiendas, incidentes y preliminares entre las autoridades administrativa y judicial, y entre dos o más administrativas, y las cuestiones de este orden cuando llegan a tener el carácter de contenciosas". Véase "Proyecto de reformas constitucionales presentado por el Sr. Castañeda”, f. 5. 
rara una lista de 15 candidatos y el Senado propusiera otros 15 , de los cuales el poder ejecutivo elegiría ocho y siete respectivamente. En las "Bases para la administración de la República" de 1853, se establecía un Consejo de 21 miembros, todos nombrados por el poder ejecutivo. El Consejo de Gobierno del Imperio se integraba con 17 integrantes nombrados por el emperador.

Durante el gobierno de Félix Zuloaga también funcionó un Consejo de Gobierno cuya existencia derivaba de un decreto del 25 de enero de $1858 .{ }^{42}$ Este Consejo se integraba por un miembro y un suplente por cada departamento -lo cual lo asemejaba al Consejo de Gobierno de la Constitución de 1824-43 y debía fungir como cuerpo consultivo para el gobierno de Zuloaga sin facultades para decidir cuestiones contencioso-administrativas. El Estatuto Orgánico Provisional de 1858, en cambio, establecía un Consejo de Gobierno integrado por 31 personas nombradas por el presidente, pero todas según su pertenencia a una clase social (art. 20). Como nota Cruz Barney, las clases imaginadas por el Estatuto de 1858 se asemejaban a las establecidas para la elección de senadores en las Bases Orgánicas, ${ }^{44}$ y como se ha demostrado arriba, a las nombradas en la Ley Electoral de 1846.

\section{LOS DERECHOS DEL HOMBRE Y DEL MEXICANO}

La cuarta diferencia del constitucionalismo de 1836, en relación con la Constitución de 1824, se encuentra en la primera ley constitucional: la declaración de los derechos "del mexicano", ausente en el código federal. Sin embargo, la ausencia de una carta de derechos en la Constitución de 1824 no significaba

\footnotetext{
42 "Decreto por la Secretaría de Gobernación", (25 ene. 1858).

${ }^{43}$ El Consejo de Gobierno de la Constitución de 1824 formaba parte del poder legislativo. Se componía de un senador por cada estado y sesionaba durante los recesos del Congreso General. Para más detalles, véase AnDrews, “Moderation vs. Conservation," pp. 160-162.

${ }^{44}$ Cruz Barney, La república central, p. 90, nota 195.
} 
que ésta rechazara la existencia de los derechos naturales, ni la inclusión de la primera ley en las Siete Leyes representaba la adhesión de los constituyentes de 1836 al constitucionalismo iusnaturalista.

A primera vista, la primera ley constitucional de 1836 no representaba un cambio muy radical comparada con la extinguida Constitución Federal. Aunque el código federal no incluyó una carta de derechos, el artículo 30 del Acta Constitutiva establecía la obligación de que la nación protegiera "por leyes sabias y justas [,] los derechos del hombre y del ciudadano", lo que parece una clara referencia a la declaración francesa de 1789. Las constituciones estatales del primer federalismo -como por ejemplo las de Tamaulipas, Jalisco y Oaxaca- señalaban que la constitución garantizaba a "[t]odo hombre que habita en el Estado, aun en clase de transeúnte, los derechos imprescriptibles de libertad, seguridad, propiedad e igualdad" e incluían otro artículo que explicitaba la libertad de imprenta (salvo en materia de religión). ${ }^{45}$ La Constitución de Yucatán, de manera excepcional entre las constituciones estatales, incluía hasta una declaración de derechos, denominados "de los yucatecos", en su artículo 9.46

Las Bases Constitucionales de 1835 indicaban que la Constitución proveniente debería respetar el derecho natural internacional - el ius gentium o derecho de gentes- en relación con los extranjeros. Los derechos de los mexicanos fueron considerados "particulares" y "civiles"; es decir, derechos que derivan de su membresía a la comunidad política constituida por las Bases, y sujetos a ser definidos (“declarados”) por una ley constitucional. La primera ley constitucional enuncia una lista de derechos civiles que se asemeja a las garantías procesales incluidas en la

${ }^{45}$ La cita es del artículo 9 de la Constitución de Tamaulipas de 1825. Véase "Constitución de las Tamaulipas", pp. 681-701.

46 “Constitución política del estado libre de Yucatán”, pp. 730-752. 
carta federal (arts. 146-156). ${ }^{47}$ Llama la atención que, al formular este artículo, los constituyentes no adoptaron la redacción del artículo 30 del Acta Constitutiva. En cambio, el artículo 2 de las Bases Constituyentes rezaba: “mientras [las personas] respeten las leyes y la religión, la nación les guardará y hará guardar los derechos".

Se puede identificar el punto de ruptura entre las Siete Leyes y la Constitución de 1824 en este abandono del reconocimiento constitucional de los derechos naturales incluido en el artículo 30 del Acta Constitutiva. Con esto, dio inicio la apertura de una nueva brecha teórica importante entre los adeptos de las Siete Leyes y los partidarios de la Constitución de 1824. Ahora no se contraponían simplemente por el tema de la soberanía, la clásica y bien documentada confrontación entre federalistas y centralistas, sino también por la conceptualización de los derechos.

Esta división se mostró en primer lugar durante los debates en torno a la primera ley y luego durante el periodo constituyente entre 1842 y 1843 . En noviembre de 1835, por ejemplo, el periódico El Anteojo publicó un largo ataque al proyecto de la primera ley en que acusaba al autor del proyecto -Francisco Manuel Sánchez de Tagle- de querer quitar al ciudadano mexicano el goce de sus derechos naturales. Las principales críticas se vertían en torno a la ausencia de un artículo que reconociera las libertades que se enumeraban en las constituciones francesas de 1791, 1793 y 1795, o bien, en la Constitución de Yucatán de 1825. Apoyándose en las críticas de Jeremy Bentham y Edmund Burke a la declaración de los derechos del hombre y del ciudadano de $1789,{ }^{48}$ Sánchez de Tagle insistió en que incluir una lista

\footnotetext{
47 El único derecho adicional enunciado en la primera ley constitucional comparada con la Constitución de 1824 es la libertad de tránsito (1ª ley, art. 2, inciso 6).

48 Sánchez de Tagle cita de manera indirecta dos textos ya clásicos: BenTHAM, "Anarchical Fallacies” y Burke, "Reflexiones sobre la Revolución francesa", pp. 39-258.
} 
de derechos naturales en la primera ley solamente llevaría a la anarquía y el desorden. Como dijeron los editores del Diario del Gobierno al publicar esta réplica, los constituyentes de 1836 consideraban que "la libertad civil es la única apetecible, y la única que debe usar en el estado de sociedad". ${ }^{49}$

La confrontación entre los dos modelos se nota más claramente al comparar los proyectos del Constituyente de 1842 con las Bases Orgánicas. Éstas seguían el camino establecido en 1836, enunciando en el artículo 9, "Derechos de los habitantes de la república”, y señalando en el artículo 10 que los extranjeros gozarían "de los derechos que les concedan las leyes y sus respectivos tratados". Los proyectos constitucionales discutidos en el Constituyente de 1842 se inclinaron por una referencia a los derechos naturales o del hombre. El artículo 7 del proyecto de la mayoría inició declarando "a todos los habitantes de la República el goce perpetuo de los derechos naturales de libertad, igualdad, seguridad y propiedad".

La diferencia entre los proyectos de 1842 y la Constitución Federal de 1824, entonces, no radica en el reconocimiento en aquéllos de los derechos naturales; tampoco fue una novedad que incluyeran un listado de derechos políticos que debía tener validez a nivel nacional..$^{50}$ En cambio, sí lo fue la decisión de los constituyentes de 1842 de introducir un mecanismo constitucional para garantizar los derechos políticos otorgados en la carta. ${ }^{51}$ Cómo entendieron los constituyentes esta garantía y

\footnotetext{
49 "La libertad civil", Diario del Gobierno de los Estados Unidos Mexicanos (10 dic. 1835). Para un análisis más a fondo de la primera ley y su relación con el liberalismo utilitario, véase Noriega, El pensamiento, t. I, pp. 148-153.

50 Aunque, desde luego, algunos de los derechos contemplados en los proyectos de 1842 fueron bastante revolucionarios, sobre todo en materia de libertad de religión. Véase una discusión de este punto en Noriega Elío, El Congreso Constituyente, pp. 100-101.

${ }^{51}$ Para una interpretación ligeramente distinta de lo transcendente de los proyectos de 1842 en materia de derechos, véase ArRoYo GARCía, La arquitectura, pp. 190-191.
} 
su relación con el muy vilipendiado cuarto poder de 1836 es el tema del último apartado.

GARANTIZAR EL ORDEN CONSTITUCIONAL:

DEL SUPREMO PODER CONSERVADOR AL AMPARO

La quinta novedad de las Siete Leyes frente a la Constitución de 1824 consistía en la creación del Supremo Poder Conservador, una institución -como su nombre proclamaba- que buscaba conservar el orden constitucional. ${ }^{52}$ La historiografía ha discutido largamente la proveniencia del concepto de un poder conservador, y es evidente que todavía no hay acuerdo entre los historiadores en este sentido.

Existen dos planteamientos principales acerca de los orígenes teóricos de este poder. El primero es el de Edmundo O'Gorman, quien señaló que los orígenes del poder se encuentran en las ideas de pensadores como Benjamin Constant para "mantener la armonía entre los tres poderes clásicos [...] y defender al individuo contra las arbitrariedades o agresiones del poder público". Subraya el hecho de que Constant imaginaba un cuarto poder en manos de un monarca, por lo que caracterizaba a la república centralista como "una monarquía disfrazada de república [...] o si se prefiere, una monarquía sin príncipe, pero con soberano colegiado" ${ }^{33}$ La hipótesis de que la inspiración de las Siete Leyes era el poder neutro de Constant fue reiterada en la tesis de maestría de Anne MacNeil ${ }^{54}$ y en un artículo reciente de Frida Osorio Gonsen..$^{55}$ Sin embargo, tanto ellas como Sordo Cedeño rechazan la idea de O'Gorman de que el Supremo Poder Conservador tenía algún origen monárquico. Para Osorio Gonsen,

52 Por lo tanto, no debe confundirse con el pensamiento conservador político.

53 O'Gorman, La supervivencia política, p. 27.

${ }_{54}$ MacNeIL, "The Supreme Harmonizing Power".

55 Osorio Gonsen, "Seeking a Balance of Power". 
la composición republicana de este poder lo separa claramente de las ideas de Constant, por ejemplo.

En cambio, David Pantoja Morán ofrece otra versión. ${ }^{56}$ En su opinión, la inspiración principal detrás de los proyectos para establecer un poder que guardara la constitucionalidad de un gobierno deriva del pensamiento de Emmanuel Sieyès y los senados conservadores de las constituciones napoleónicas de 1799,1802 y 1804 . Señala que la idea del senado conservador apareció en varias constituciones latinoamericanas y fue discutida en México numerosas veces a partir de 1821.

El desacuerdo en la historiografía deriva del hecho de que el Supremo Poder Conservador ostentaba una multitud de facultades, algunas de las cuales tienen raíces en el pensamiento constitucional francés en sus diversas manifestaciones, y algunas eran completamente novedosas y únicas en México. Para desentrañar este aspecto de la historia del Supremo Poder Conservador, se clasificarán las facultades del Conservador en tres funciones principales. La primera de ellas era el control de la constitucionalidad. En segundo lugar, el contrapeso de los demás poderes. Finalmente, el Conservador tenía una gama de facultades que se puede caracterizar como voz (o representación última) de la nación y poder constituyente permanente. De esta manera, se podrán entender los antecedentes ideológicos de estas facultades y cómo perduraron (o no) en los proyectos constitucionales posteriores.

La función de control de la constitucionalidad atribuida al Supremo Poder Conservador deriva de la prerrogativa para anular leyes y decretos que no respetaban la Constitución. De acuerdo con la segunda ley constitucional (art. 12), este atributo sólo podría ejercerse si así lo pedían el poder ejecutivo, la Suprema Corte de Justicia o 18 congresistas (inciso 1). El Supremo Poder Conservador también podría declarar la nulidad de actos del poder ejecutivo que atentaran contra la Constitución, si así

56 Pantoja Morán, El Supremo Poder. 
lo solicitaban el Congreso o la Suprema Corte (inciso 2). Los poderes legislativo y ejecutivo podrían pedir que el Supremo Poder Conservador anulara actos de la Suprema Corte "en el caso de usurpación de facultades" (inciso 3).

Examinamos el papel del Supremo Poder Conservador como contrapeso en un apartado anterior: podría suspender el ejercicio de los tres poderes tradicionales si alguno de los demás lo excitara para hacerlo. Podría declarar "la incapacidad física o moral del presidente de la República", suspender a la Suprema Corte de Justicia en caso de que sus actos incitaran al desorden público, y suspender hasta por dos meses al Congreso General. Si una mayoría de juntas departamentales así lo pidieran, también podría el Poder Conservador exigir al presidente que renovara por completo su ministerio.

Finalmente, el Supremo Poder Conservador debería funcionar como representante último de la nación y poder constituyente permanente. Podía restablecer los poderes cuando hubieran "sido disueltos revolucionariamente", para declarar la voluntad de la nación en cualquier tema a petición del poder legislativo y uno de los otros poderes, y para sancionar cualquier reforma de la Constitución.

El análisis histórico resumido arriba señala claramente las similitudes entre las facultades del Supremo Poder Conservador $\mathrm{y}$ las instituciones propuestas por Constant, Sieyès y los senados conservadores franceses. No es tan evidente en este análisis qué tanto el conjunto de las prerrogativas del Supremo Poder Conservador lo separaba de aquellas instituciones. Esto se ve sólo cuando se examina el desempeño de esta institución durante la vigencia de las Siete Leyes, pues es evidente que el órgano mexicano funcionaba de manera muy distinta a sus semejantes francesas. ${ }^{57}$

57 Este punto se desarrolla más en Catherine Andrews, "The Constitution Will Be Our Last Hope in the Momentary Storm". Moderating and 
La novedad fundamental del Supremo Poder Conservador es su facultad para anular legislación sancionada: anuló, entre otras leyes, la ley de ladrones en 1840, una ley que hubiera permitido que tribunales militares juzgaran a los acusados de delitos de fuero común..$^{58}$ En contraste, el quehacer del jurado constitucional de Sieyès se limitaba a juzgar la constitucionalidad de los actos de los demás poderes a partir de una denuncia gubernamental, y no tenía la facultad de invalidar o declarar inconstitucionales las leyes sancionadas. ${ }^{59}$ Por esta razón Michel Troper rechaza cualquiera interpretación del jurado constitucional como precursor de las cortes constitucionales contemporáneas. ${ }^{60}$

Conservative Powers in Mexico (1821-1841)", ponencia presentada en el coloquio internacional, Constitutional History: Comparative Perspectives, en la Facultad de Jurisprudencia de la Universidad de Bolonia, Italia, del 13 al 14 de noviembre de 2017.

58 La anulación de la ley de 1840 fue rechazada y refutada por el gobierno de Anastasio Bustamante. Véase "Expediente formado para que se excite al Supremo Poder Conservador para que declare nula la orden del Supremo Gobierno del presente año por la que autorizó a los comandos generales para juzgar a los ladrones y asesinos”, SCJN, exp. 4138-1839; PÉrez JoHnston, "El Supremo Poder" y Andrews, Entre la espada, pp. 280-285. Dio pie a un intercambio de opiniones entre los poderes sobre los límites del actuar del Conservador, como se ve en Documentos impresos y en Manifestación. En el marco de la controversia, se publicó la ley del 11 de julio de 1840 que clarificaba el quórum necesario para que funcionara el Poder Conservador. Véase "Julio 11 de 1840. Organización y atribuciones del Poder Conservador", en Dublán y Lozano, Legislación, vol. 3, p. 723. Lucas Alamán, como presidente del Consejo de Gobierno, respondió a la anulación en el siguiente dictamen, argumentando que el Poder Conservador no debía tener la facultad de anular las leyes que interpretaban la Constitución, pues significaba "la inversión del orden constitucional, a saber, que el Conservador y no el Congreso sea el intérprete seguro y eficaz de la Constitución”. "Sobre la declaración que ha hecho el Supremo Poder Conservador de nulidad de algunos artículos de la ley de 11 de julio aclaratoria de la ley constitucional” (7 sept. 1840), AGN, Justicia, vol. 203, leg. 72, exp. 3, ff. 42-78.

59 SIEYÈs, Les discours de Sieyès.

60 Troper, "Sieyès et la hiérarchie”, pp. 25-42. Para esta cuestión también véase Goldoni, “At the Origins”, pp. 211-34. 
El Senado Conservador de la Constitución del año VIII (1799) tampoco podía anular leyes sancionadas, sólo actos. El Senado de la Constitución del año XII (1804) podía emitir dictamen en contra de un proyecto de ley si un senador consideraba que no había "sido deliberado en las formas prescritas por las constituciones del Imperio, los reglamentos y las leyes” (art. 70), pero correspondía al emperador tomar la decisión final sobre promulgar o no una ley. ${ }^{61}$ En este caso, no era el contenido de una ley $-\mathrm{y}$ su congruencia con la constitución- lo que ameritaba un dictamen negativo, sino en los casos en que un proyecto de ley no hubiera seguido el debido camino para su promulgación.

En segundo lugar, el papel de contrapeso o de moderador que los constituyentes de 1836 otorgaron al Supremo Poder Conservador no tiene parangón en el desempeño de los senados conservadores franceses. Es cierto que en la Constitución del año X (1802), por ejemplo, el Senado tenía la facultad de disolver las cámaras legislativas (art. 55 inciso 5) y nombrar a los cónsules (art. 55, inciso 6), pero, a su vez, los cónsules eran integrantes del Senado y el primer cónsul-Napoleón mismo- fungía como su presidente. Por lo tanto, tienen razón los historiadores al señalar que hay más similitud entre las facultades de contrapeso del Supremo Poder Conservador y el poder neutro de Benjamin Constant. El monarca constitucional "neutro" de Constant ostentaba las facultades del rey británico (incluyendo la prerrogativa de disolver las cámaras y quitar a los ministros y el jefe de gobierno). Este monarca formaba parte de un plan más amplio que el francés para introducir pesos y contrapesos a la Constitución francesa, y sin duda, los constituyentes de 1836 leyeron sus tratados. ${ }^{62}$ De todos modos, hay que señalar que el Supremo

${ }^{61}$ Las constituciones de 1795, 1799, 1802 y 1804 se pueden consultar en GoDECHOT, Les Constitutions.

${ }^{62}$ Este punto se desarrolla más en Catherine Andrews, "The Constitution Will Be Our Last Hope in the Momentary Storm". Moderating and Conservative Powers in Mexico (1821-1841)," ponencia presentada en el coloquio 
Poder Conservador respondía asimismo a la exigencia de varios políticos desde 1821 de que la Constitución debería incluir una institución que sirviera de contrapeso tanto al poder legislativo como al ejecutivo. ${ }^{63}$

Finalmente, es cierto que los senados conservadores napoleónicos también ostentaban facultades constituyentes. Adoptaron una práctica de la República romana tardía: los decretos del Senado. En la República romana, un senatus consultum era un decreto emitido por el Senado que aconsejaba a los cónsules y magistrados en el ejercicio de sus funciones. Un senatus consultum ultimum facultaban al cónsul o cónsules para tomar las medidas necesarias en defensa del bienestar de la República. Se entendía que esto incluía la facultad de actuar fuera de las normas legales. ${ }^{64}$ Los senatus-consultes o decretos del Senado Conservador adaptaron esta práctica para el primer y segundo imperios franceses. De acuerdo con la Constitución del año X (1802), por ejemplo, los senatus- consultes organiques fueron decretos que modificaron la constitución o bien hicieron declaraciones sobre asuntos constitucionales no contemplados por la Constitución. Los decretos simples del Senado Conservador regulaban la aplicación de la Constitución (arts. 54 y 55). Las constituciones de los años X (1802) y XII (1804) y el Acto adicional de 1814 fueron emitidos mediante un senatus-consulte, por ejemplo.

Si bien la función del poder constituyente del Supremo Poder Conservador parece similar en teoría a los senados conservadores napoleónicos, la composición y elección de la institución

internacional, Constitutional History: Comparative Perspectives, en la Facultad de Jurisprudencia de la Universidad de Bolonia, Italia, del 13 al 14 de noviembre de 2017".

${ }^{63}$ Véase ANDREws, "Moderation vs. Conservation".

${ }^{64}$ Una lectura obligatoria acerca del pensamiento constitucional de la República tardía romana y su influencia en el desarrollo del constitucionalismo atlántico a partir del siglo Xvi se encuentra en STRAUMANN, Crisis and Constitutionalism. 
mexicana la separaban de los senados franceses. Como se comentó líneas arriba, el Supremo Poder Conservador estaba integrado por cinco miembros electos, quienes ocupaban su puesto durante un máximo de seis años, renovándose por dos escaños cada dos años. Las juntas departamentales postulaban candidatos para las vacantes, la Cámara de Diputados integraba una terna con base en los nombres remitidos por las juntas y el Senado nombraba a los integrantes con base en esta lista. Los senados conservadores de las constituciones de 1799, 1802 y 1804 eran mucho más grandes (con más de 80 senadores cada uno) y establecieron senadores inamovibles. En la Constitución de 1799 el Senado mismo nombraba a sus integrantes a partir de listas mandadas por los colegios electorales (art. 15); en la de 1802, el primer cónsul -Napoleón- nombraba a los integrantes. El primer cónsul también ocupaba la presidencia del cuerpo (arts. 63 y 64). En la Constitución de 1804, los senadores incluyeron miembros de la familia real de Napoleón, representantes de las "grandes familias", un número ilimitado de candidatos escogidos por el emperador, y otros 80 nombrados por el emperador a partir de listas entregadas por los colegios electorales (art. 57).

En otras palabras, los senados conservadores fueron asambleas grandes, lo que limitaba su agilidad política, e inamovibles; mientras que el Supremo Poder Conservador era un cuerpo pequeño en constante renovación. Asimismo, el diseño de los senados conservadores - sobre todo a partir de 1802- no cuidaba su independencia del poder ejecutivo, sino que estaban integrados y presididos por representantes de este poder. No debe sorprender, por ende, la desviación de su función de poder constituyente para permitir a Napoleón saltarse la Constitución. ${ }^{65}$ En

${ }_{65}$ Pantoja Morán detalla los usos que hacía Napoleón de los senados en PANtoja Morán, El Supremo, pp. 261-270. 
cambio, el Supremo Poder Conservador era independiente del poder ejecutivo tanto en su composición como en su elección.

Tampoco se puede equiparar el actuar del Supremo Poder Conservador con los senados conservadores franceses. En repetidas ocasiones el Supremo Poder Conservador se negó a dar facultades extraordinarias al presidente Anastasio Bustamante, incluso en circunstancias tan graves como la invasión de Veracruz por parte de los franceses. Durante la abortada revolución de los federalistas moderados en 1838, en la que participaba el presidente junto con Manuel Gómez Pedraza, y en la que los revoltosos pidieron al Supremo Poder Conservador emitir una opinión a favor de reformar la Constitución extraordinariamente, el cuarto poder se negó siquiera a recibir la demanda, pues no se había presentado en la forma mandada por la Constitución. ${ }^{66}$ Durante casi toda la vigencia de las Siete Leyes, el Supremo Poder Conservador tomó en serio su papel de guardián constitucional. ${ }^{67}$ Además de anular legislación, también revocó varios actos del gobierno, como la importación extralegal de hilaza de algodón por órdenes del ministro de Guerra, Juan Nepomuceno Almonte, para fabricar uniformes para el ejército en 1840, por ejemplo; o bien, un decreto del secretario de Guerra mediante el cual nombró a un hijo del compadre del presidente Bustamante juez de letras en Tlalpan. ${ }^{6}$

66 Andrews, Entre la espada, pp. 240-245.

67 La excepción sería durante el breve interinato de Antonio López de Santa Anna (marzo a junio de 1839), durante el cual el presidente en funciones gobernó sin cuidarse de las normas de la Constitución de 1836. Pero, de nuevo, no se puede decir que el Supremo Poder Conservador apoyó las acciones de López de Santa Anna, más bien se vio repasado e ignorado. Véase Andrews, Entre la espada, pp. 271-272 y Osorio Gonsen, "Seeking a Balance”, pp. 144-145. 68 "Decreto en oficio se muestra la declaración del Supremo Poder Conservador sobre nulidad el contrato que el Supremo Gobierno celebró para proporcionarse 130000 libras esterlinas en Londres”, SCJN, exp. 3964-1839; “Toca a lo relativo a la reposición del Lic. D. Fco. Barrera y Prieto al Juzgado de Letras 
Visto en conjunto, entonces, la composición del Supremo Poder Conservador, así como sus facultades y actuación, claramente lo diferencian del poder neutro de Constant, del jurado constitucional de Sieyès y de los senados conservadores franceses. Por encima de cualquiera otra consideración, la prerrogativa para anular legislación era innovador tanto para la historia constitucional mexicana como para la latinoamericana, cuyos senados conservadores tampoco contemplaron dicha función. ${ }^{69}$ Asimismo, las facultades de poder constituyente ejercidas por el Supremo Poder Conservador fueron radicalmente diferentes a las ejercidas por los senados conservadores durante el Consulado y el Primer Imperio, principalmente la autonomía e independencia del Supremo Poder Conservador frente al poder ejecutivo.

La caracterización del Supremo Poder Conservador después de 1836 como un monstruo deriva de la oposición generalizada a las funciones del poder constituyente. Los legisladores del Congreso General y los políticos de los estados argumentaron que el poder constituyente del Supremo Poder Conservador le impedía ser la institución guardiana de la constitucionalidad, pues siempre sería un poder extraconstitucional. Sencillamente, el Supremo Poder Conservador estaba "revestido de una omnipotencia política [que lo hacía] el árbitro de los destinos del Estado, sin que [hubiera una] autoridad que moder[ara] sus abusos", ${ }^{70}$ por lo que siempre existiría el riesgo de que degenerara en una

de Tlalpan”, SCJN, exp. 2475-1838. Osorio Gonsen, "Seeking a Balance," pp. 140-141, y Pantoja Morán, El Supremo Poder, pp. 382-383.

${ }_{69}$ Pantoja Morán señala acertadamente que hubo senados conservadores en varios países latinoamericanos durante la primera época de republicanismo en la región: Pantoja Morán, El Supremo Poder, p. 355. Para más detalles véase Andrews, "Moderation vs. Conservation", pp. 159-161, y TimmerMANN, "El concepto de 'gobierno moderado", pp. 5-25.

70 "Proyecto de constitución presentado a la legislatura de Yucatán”, p. 15. 
institución que respaldara la dictadura, tal y como los senados conservadores franceses habían hecho.

Dicho esto, la mayoría de sus críticos querían conservar tanto la función de control constitucional como la de contrapeso efectivo a los demás poderes; simplemente quería dividir estas facultades entre los tres poderes clásicos. Para cuando se discutía la reforma a las Siete Leyes, en 1840, ya circulaba en México La democracia en América de Alexis de Tocqueville, obra que tendría larga sombra en el debate político de las siguientes décadas. La comparación que realizó Tocqueville entre el constitucionalismo francés y la constitución estadounidense en cuanto a sus respectivas habilidades para frenar el abuso por parte de las autoridades políticas tenía mucha relevancia para el debate sobre el futuro del Supremo Poder Conservador, y fue citada - de manera indirecta la mayoría de veces- reiteradamente en los argumentos tanto en pro como en contra del cuarto poder. ${ }^{71}$

En el dictamen del Consejo de Gobierno sobre el proyecto de reforma a las Siete Leyes publicado en el verano 1841 se defendió la necesidad de que las funciones del Supremo Poder Conservador "se deposit[aran] en algún individuo o corporación", como "la Corte Suprema de Justicia” de Estados Unidos o los reyes constitucionales europeos. ${ }^{72}$ El diputado Pedro Ramírez, miembro de la comisión de la Cámara de Diputados encargada de reformar las Siete Leyes, abogó por la desaparición del Supremo Poder Conservador. Propuso seguir el ejemplo estadounidense de facultar a la Suprema Corte para declarar la inconstitucionalidad de las leyes. Atribuyó esta idea a " $[\mathrm{u}] \mathrm{na}$ obra moderna, que hizo mucho ruido en Francia" y que "casi se ocupa toda en demostrar que la paz y la tranquilidad de la

71 Tocqueville, La democracia, pp. 106-110.

72 “Parte oficial. Gobierno General. Ministerio de lo Interior”, Diario del Gobierno de la República Mexicana (25 ago. 1841). 
República del Norte no se debe a otra cosa que a la influencia que ejerce en ella su Corte de Justicia". ${ }^{73}$

A pesar de esta declaración, Ramírez no propuso reformar las Siete Leyes para que se adoptara el principio de judicial revierw tal y como lo describe Tocqueville; es decir, la facultad de los ciudadanos de cuestionar la constitucionalidad de una ley en los tribunales federales amplios. Quería conservar la prerrogativa establecida en las leyes constitucionales para que el derecho de impulsar una queja se limitara a los poderes de gobierno y la facultad de sentenciar se concentrara únicamente en la Suprema Corte. A saber: "cuando cierto número de Diputados, de Senadores, de juntas Departamentales reclaman alguna ley o acto del Ejecutivo, como opuesto a la Constitución, se diese a ese reclamo el carácter de contencioso y se sometiese al fallo de la Corte de Justicia". ${ }^{74}$

Durante los debates de 1842, se presentó otra manera de plantear la división de poderes para que las facultades del Supremo Poder Conservador se encargaran a los demás poderes. Por ejemplo, en el segundo proyecto de la comisión constitucional de 1842, se propuso un arreglo por el que la Cámara de Diputados fuera facultada para anular los actos de la Suprema Corte de Justicia o de los tribunales de los departamentos (art. 140); mientras que el Senado podría anular los actos del poder ejecutivo y las leyes de las asambleas departamentales a petición expresa del gobernador (art. 141). Sin embargo, dicho proyecto no incluyó un mecanismo para anular la legislación sancionada.

La posibilidad de anular legislación reapareció en el Acta de Reforma de 1847. En el artículo 23, el Acta especificó que si "el presidente $[\ldots]$ o [...] diez diputados o seis senadores" reclamaban una ley como "anticonstitucional”, la Suprema Corte debería consultar a las juntas departamentales. Quedaría

73 "Voto particular del diputado José Fernando Ramírez", p. 269.

74 “Voto particular del diputado José Fernando Ramírez”, p. 269. 
"anulada la ley si así lo resolviere la mayoría de las legislaturas". Al inverso, el artículo 22 del Acta de Reforma volvió a encargar al Congreso General la facultad de anular las leyes de los estados. De esta manera se establecía un equilibrio constitucional en el que los estados vigilarían la actuación de los poderes federales y los federales la de los estados, ambos con la facultad de anular la legislación del otro.

Los artículos 22 y 23 del Acta de Reformas no se incluyeron en la Constitución de 1857. El diputado Mariano Arizcorreta defendió su continuación en el proyecto de constitución que presentó ante el Constituyente en julio de 1856, pero la idea no encontró apoyo. ${ }^{75}$ Hay que mencionar, no obstante, que se incluyó en el artículo 127 la previsión de que tres cuartas partes de las legislaturas de los estados tuvieran que aprobar cualquiera reforma constitucional, de modo que se conservó algo del equilibrio de 1847.

La otra propuesta de control constitucional que se ideó en el contexto del debate acerca de la reforma de las Siete Leyes apareció en el proyecto de constitución que escribió Manuel Crescencio Rejón para el estado de Yucatán en 1841. Al igual que Ramírez, Rejón empezó su propuesta de reforma con una referencia a las facultades de la Suprema Corte de Justicia de Estados Unidos, e insistió -siguiendo claramente los argumentos de Tocqueville- en que éstas "no solo [son] atribuciones judiciales, sino también [...] son casi enteramente políticas”. En el proyecto, Rejón propuso revestir “a la Corte Suprema de Justicia de un poder suficiente, para oponerse a las providencias anticonstitucionales del Congreso, y a las ilegales del Poder Ejecutivo, en las ofensas que hagan a los derechos políticos y civiles de los habitantes del Estado". De esta manera,

75 Véase "Sesión secreta extraordinaria del 23 de junio de 1856", p. 288. Para una discusión de este proyecto constitucional, consúltese ARroYo GARCíA, La arquitectura, pp. 301-302. 
argumentaba, se haría “innecesaria la creación de un poder conservador". 76

El proyecto de Rejón y la subsiguiente Constitución de Yucatán de 1841 plantearon la necesidad de vincular la defensa de la constitucionalidad con la garantía de los derechos constitucionales. Así, la Constitución de Yucatán ya no habló de la anulación de los actos judiciales ni ejecutivos a la manera de las Siete Leyes. Empezó con un apartado titulado "Garantías individuales", cuyo artículo 7 enlistó los mismos derechos que garantizaba la primera ley constitucional bajo la descripción: “derechos de todo habitante del estado, sea nacional o extranjero”, para luego establecer en los artículos 8 y 9 que "los jueces de primera instancia ampararán en el goce de los derechos [...] a los que les pidan su protección".

El proyecto de la minoría de 1842 repitió la idea de una garantía constitucional a los derechos. La diferencia, como se notó en el apartado anterior, era que el proyecto de Otero reintrodujo el reconocimiento de los derechos naturales, algo no contemplado en el proyecto de Rejón, quien seguía la lógica de la primera ley constitucional de 1836. El segundo proyecto de 1842 establecía que "todo acto de los poderes legislativo o ejecutivo de alguno de los estados" podría ser reclamado ante la Suprema Corte (art. 150). El recurso del amparo que proponían los constituyentes de 1842 reapareció en el Acta de Reforma de 1847 con la famosa aclaración en el artículo 25 de que las sentencias de la Corte en materia de amparo se limitaban a "impartir su protección en el caso particular sobre el que verse el proceso, sin hacer ninguna declaración general respecto de la ley o del acto que lo motivare". El motivo probable de esta delimitación descansaba precisamente en el mecanismo de anulación de ley que, como se acaba de demostrar, también permitía el Acta de Reforma de 1847.

76 "Proyecto de constitución presentado a la legislatura de Yucatán," pp. $15-16$. 


\section{CONSIDERACIONES FINALES}

Al comenzar este artículo, se argumentó que la interpretación todavía prevaleciente en la historiografía acerca del legado de las Siete Leyes es la de Alfonso Noriega, quien veía la Constitución de 1836 como el primer paso hacia "el despotismo constitucional" de las Bases Orgánicas, y al proyecto monárquico posterior de los conservadores. En esta interpretación, las Siete Leyes no simplemente es un proyecto distinto al proyecto federalista, sino que representa su antítesis. Gracias a los argumentos esbozados hasta ahora, debe haber quedado claro que esta hipótesis no se puede sostener. Por un lado, es cierto que el legado de las Siete Leyes se evidencia en el constitucionalismo conservador, sobre todo en las Bases Orgánicas, y posteriormente en el desarrollo de los proyectos para un Consejo de Estado. Pero no es fundado argumentar que se plantearon en 1836 todas las semillas del constitucionalismo conservador de las décadas de 1850 y 1860. Parecen más importante las aportaciones de Teodosio Lares y Marcelino Castañeda en el diseño de los Consejos de Estado, por ejemplo.

Por otro lado, las Siete Leyes tuvieron un gran impacto en el desarrollo del pensamiento liberal-federal que dio pie tanto al Acta de Reforma de 1847 como a la Constitución de 1857. Los debates en torno a la Constitución de 1836 y a su reforma dirigieron en muchos sentidos la discusión posterior, sobre todo en la cuestión del control constitucional, así como en el tema de la representación. La insistencia de las Bases Constitucionales de 1835 en afirmar la soberanía nacional permitió a las Siete Leyes y a las subsiguientes constituciones del siglo XIX rechazar el confederalismo de manera definitiva.

En cuanto a la cuestión del control de la constitucionalidad, el seguimiento del impacto de las Siete Leyes evidencia que el Acta de Reforma de 1847 contemplaba dos mecanismos distintos: anular legislación y el amparo. La historia del Supremo 
Poder Conservador da argumentos para entender por qué los políticos de las décadas de 1840 y 1850 no abogaban por seguir el modelo estadounidense de judicial review al pie de la letra, tal y como se intentó en Argentina, por ejemplo. ${ }^{77}$ México tenía su propia historia en materia de control constitucional, la cual condicionó la manera en que los políticos mexicanos recibieron y entendieron la presentación que hacía Tocqueville del modelo estadounidense.

De esta historia, también se derivó la famosa "fórmula Otero", que limitaba el impacto de una resolución judicial de un recurso de amparo al quejoso. Esta limitación obedecía a la existencia, en la misma Acta de Reforma, de la provisión de anular legislación de manera general por otra vía. Si por los artículos 22 y 23, serían el Congreso General o las legislaturas de los estados los encargados de declarar nula una ley estatal o una ley federal, evidentemente no convenía extender la misma facultad a la Suprema Corte. La decisión de los constituyentes en 1856 de rechazar la incorporación de este mecanismo a la Constitución de 1857 cerró definitivamente esta avenida de control de la constitucionalidad en México. De esta manera, el legado más importante de las Siete Leyes quedó truncado.

\section{SIGLAS Y REFERENCIAS}

AGN Archivo General de la Nación, Gobernación, Justicia, Ciudad de México, México.

SCJN Suprema Corte de Justicia de la Nación, Archivo histórico, Ciudad de México, México.

“Acta Constitutiva de la Federación Mexicana”, en Villegas Moreno y Porrúa Venero (coords.), 1989, t. 2, pp. 309-315.

"Acta Constitutiva y de Reformas, sancionada por el Congreso Extraordinario Constituyente de los Estados Unidos Mexicanos, 21 de mayo de 1847", en Villegas Moreno y Porrúa Venero (coords.) 1989, t. 2, pp. 408-417.

77 Véase Zimmermann, “Translations” y Miller, "Echoes”. 
Aguilar Rivera, José Antonio, "La convocatoria, las elecciones y el congreso extraordinario de 1846”, en Historia Mexicana, LXI: 2 (242) (oct.-dic. 2011), pp. 531-588.

Andrews, Catherine, "Discusiones en torno a la reforma de la Constitución Federal de 1824 durante el primer gobierno de Anastasio Bustamante (18301832)", en Historia Mexicana, LVI: 1 (221) (jul.-sep. 2006), pp. 71-116.

ANDRews, Catherine, Entre la espada y la constitución. El general Anastacio Bustamante (1780-1853), Tamaulipas Universidad Autónoma de Tamaulipas, Instituto de Investigaciones Parlamentarias del H. Congreso del Estado de Tamaulipas, 2008.

AnDREws, Catherine, "El debate político de la década de 1830 y los orígenes de las Siete Leyes", en Noriega Elío y Salmerón (eds.), 2009, pp. 111-134.

Andrews, Catherine, De Cádiz a Querétaro. Historiografía y bibliografía del constitucionalismo mexicano, México, Fondo de Cultura Económica, 2017.

Andrews, Catherine, "La Constitución de 1824 en su contexto: propuestas para la división de poderes en México (1823-1824)”, en Rojas (coord.), 2017, pp. $75-108$.

Andrews, Catherine, "Moderation vs. Conservation: State Councils and Senates in Mexico's First Constitutional Proposals", en Mexican Studies/ Estudios Mexicanos, 33: 1 (2017) pp. 153-166.

Arrillaga, Basilio José, Recopilación de leyes, decretos, bandos, reglamentos, circulares y providencias de los supremos poderes y otras autoridades de la República Mexicana, México, Imprenta de A. Boix, a cargo de M. Zornoza, 1864,

Arroyo García, Israel, "La arquitectura de la república mexicana, 18221857”, en LANDAVAZo y SÁnchez AndRÉs (coords.), 2008, pp. 73-132.

Arroyo García, Israel, La arquitectura del Estado mexicano: formas de gobierno, representación política y ciudadanía, 1821-1857, México, Instituto Mora, 2011.

"Bases constitucionales expedidas por el Congreso Constituyente, 15 de diciembre de 1835”, en Villegas Moreno y Porrúa Venero (coords.), 1997, t. 2, pp. 197-199. 
Bases adoptadas por el ejército de operaciones en Tacubaya el día 28 del mes de setiembre último y que han servido para la organizacion del Gobierno provisional de la República, después del convenio del dia 6 del corriente entre los Exmos. Sres. Generales en gefe de las fuerzas beligerantes, México, Imprenta del Águila, dirigida por José Ximeno, calle de Medinas núm. 6, 1841.

"Bases para la administración de la República, hasta la promulgación de la Constitución, 22 de abril de 1853”, en Villegas Moreno y Porrúa Venero (coords.), 1997, t. 2, pp. 435-441.

Bentham, Jeremy, "Anarchical Fallacies: Being an Examination of the Declaration issued during the French Revolution", en John BRowrig (ed.), The Works of Jeremy Bentham, Edimburgo, William Tait, 1838-1843.

Burke, Edmund, “Reflexiones sobre la Revolución francesa”, en Textos políticos, traducción de Vicente Herrero, México, Fondo de Cultura Económica, 1996, pp. 39-258.

"Constitución de los Estados Unidos Mexicanos, 5 de febrero de 1857", en Villegas Moreno y Porrúa Venero (coords.), 1997, t. 2, pp. 529-545.

"Constitución federal de los Estados Unidos Mexicanos sancionada por el Congreso General Constituyente, 4 de octubre de 1824", en Villegas Moreno y Porrúa Venero (coords.), 1989, t. 2, pp. 335-361.

“Constitución política del estado libre de Yucatán”, en Villegas Moreno y Porrúa Venero (coords.), 1989 t. 2, pp. 730-752.

“Constitución de las Tamaulipas”, en Villegas Moreno y Porrúa Venero (coords.), 1989, t. 2, pp. 681-701.

Cruz Barney, Óscar, La república central de Félix Zuloaga y el Estatuto Orgánico Provisional de la República de 1858, México, Universidad Nacional Autónoma de México, 2009.

"Decreto por la Secretaría de Gobernación del 25 de enero de 1858. Consejo de Gobierno. Su organización”, en ArRillaga, 1864, pp. 13-16.

"Dictamen de la mayoría y de la comisión de constitución y voto particular de Mariano Otero", en Villegas Moreno y Porrúa Venero (coords.), 1997, t. 2, pp. 382-408. 
Dublán Manuel y José María Lozano, La legislación mexicana, CD-ROM, Mario A. Téllez G. y José López Fontes (comps.), México, Toluca, Suprema Corte de Justicia de la Nación, El Colegio de México, Escuela Libre de Derecho, Tribunal Superior de Justicia del Estado de México, 2004.

Duve, Thomas (ed.), Entanglements in Legal History: Conceptual Approaches, Global Perspectives on Legal History, Fráncfort, Max Planck Institute for European Legal History, 2014.

Estatuto provisional del Imperio mexicano, México, Imprenta de J. M. Andrade y F. Escalante, 1865.

Ferrer Mac-Gregor, Eduardo y Arturo Zaldívar Lelo de Larrea (coords.), La ciencia del derecho procesal constitucional. Ensayos en homenaje a Héctor Fix-Zamudio en sus cincuenta años como investigador del derecho, México, Universidad Nacional Autónoma de México, 2008.

Fowler, Will, Independent Mexico: The Pronunciamiento in The Age of Santa Anna, 1821-1858, Lincoln, University of Nebraska Press, 2016.

Godechot, Jacques, Les Constitutions de la France depuis 1789, París, Flammarion, 1998.

Goldoni, Marco, "At the Origins of Constitutional Review: Sieyès' Constitutional Jury and the Taming of Constituent Power", en Oxford Journal of Legal Studies, 32: 2 (2012), pp. 211-234.

Herrera y Lasso, Manuel, “Centralismo y federalismo, 1814-1843", en Derechos del pueblo mexicano. México a través de sus constituciones. Historia constitucional, México, Cámara de Diputados, LII Legislatura, 1985, vol. II, pp.11-114.

Landavazo, Marco Antonio y Agustín Sánchez Andrés (coords.), Experiencias republicanas y monárquicas en México, América Latina y España, Morelia, Universidad Michoacana de San Nicolás de Hidalgo, 2008.

Lares, Teodosio, "Ley para el arreglo de lo contencioso administrativo", en Revista de la Facultad de Derecho, 21: 83-84 (1971), pp. 523-537: https:// revistas-colaboracion.juridicas.unam.mx/index.php/rev-facultad-derecho$\mathrm{mx} /$ article/view/26731/24088, consultado 12 de febrero de 2018.

"Ley sobre lo contencioso administrativo", en Boletín de las leyes del Imperio Mexicano: Comprende las leyes, decretos y reglamentos generales, números del 
1 al 176, expedidos por el Emperador Maximiliano desde 1o. de julio hasta 31 de diciembre de 1865, México, Andrade y Escalante, 1866, pp. 224-240.

“Leyes constitucionales, 20 de diciembre de 1836", en Villegas Moreno y Porrúa Venero (coords.), 1997, t. 2, pp. 202-234.

Lerdo de Tejada, Sebastián, “Iniciativa que el gobierno presenta al soberano Congreso sobre puntos de reformas y adiciones a la Constitución Política de la República Mexicana, sancionada en 5 de febrero de 1857 (13 de diciembre de 1867)", en Benito Jú́rez, Documentos, discursos y correspondencia, selección y notas de Jorge L. Tamayo, ed. digital coord. Héctor Cuauhtémoc Hernández Silva, México, Senado de la República, Instituto Nacional de Estudios Históricos sobre la Revolución Mexicana, Universidad Autónoma Metropolitana-Azcapotzalco, 2017: http://juarez.mhiel.mx/, consultado el 10 de febrero de 2018.

Limón EnRíquez, Ángel Israel, “El Senado como poder moderador del legislativo: la suerte de una reforma constitucional en 1893", tesis de licenciatura en historia, Instituto Mora, 2017.

Luna Argudín, María, El Congreso y la política mexicana 1857-1911, México, El Colegio de México, Fondo de Cultura Económica, 2006.

MacNeIL, Anne Worthington Surget, “The Supreme Harmonizing Power (El Supremo Poder Conservador), 1837-1841”, tesis de maestría, Texas, Universidad de Texas, 1969.

Miller, Jonathan M., "Echoes from the South: Argentina's Early Legislative Debates on U.S.-Style Judicial Review", en Willamette Law Review, 48 (2012), pp. 473-496.

Moreno Valle, Lucina, Catálogo de la Colección Lafragua de la Biblioteca Nacional de México, México, Universidad Nacional Autónoma de México, 1975.

Noriega, Alfonso, Elpensamiento conservador y el conservadurismo mexicano, México, Universidad Nacional Autónoma de México, 1972, 2 volúmenes.

Noriega Elío, Cecilia, El Congreso Constituyente de 1842, México, Universidad Nacional Autónoma de México, 1986. 
Noriega Elío, Cecilia y Alicia Salmerón (eds.), México: un siglo de historia constitucional (1808-1917), México, Instituto Mora, Suprema Corte de Justicia, 2009.

O'Gorman, Edmundo, La supervivencia política novo-hispana. Monarquia o república, México, Universidad Iberoamericana, 1986.

Osorio Gonsen, Frida, "Seeking a Balance of Power through a Neutral Third Party Mechanism. The Mexican Supreme Conservative Power (1836-1841)”, en Mexican Studies/Estudios Mexicanos, 33: 1 (2017), pp. 125-152.

Pantoja Morán, David, El Supremo Poder Conservador. El diseño institucional en las primeras constituciones mexicanas, México, El Colegio de México, El Colegio de Michoacán, 2005.

Pantoja Morán, David, "La Constitución de 1857 y su interludio parlamentario", en Historia Mexicana, LVII: 4 (228) (abr.-jun. 2008), pp. 1045-1106.

Pérez Johnston, Raul, "El Supremo Poder Conservador y su sentencia de muerte. La ley sobre ladrones del 13 de marzo de 1840", en Ferrer MacGregor y Zaldívar Lelo de Larrea (coords.), 2008, pp. 437-476.

"Proyecto de bases de organización para la República Mexicana presentado a la honorable junta nacional legislativa, por la comisión nombrada al efecto", en Diario del Gobierno de la República Mexicana (10 abr. 1843).

"Primer proyecto de Constitución. Constitución política de la República Mexicana, 25 de agosto de 1842", en Villegas Moreno y Porrúa Venero (coords.), 1997, t. 2, pp. 274-299.

"Proyecto de constitución. Constitución política de la República Mexicana, 16 de junio de 1856", en Villegas Moreno y Porrúa Venero (coords.), 1997, t. 2, pp. 471-486.

"Proyecto de constitución presentado a la legislatura de Yucatán por su comisión de reformas para la administración interior del Estado (15 de enero de 1841)", en Josefina Zoraida Vázquez (comp.), Planes de la Nación Mexicana, México, Senado de la República, 1987, pp. 9-18.

“Proyecto de reforma, 30 de junio de 1840", en Villegas Moreno y Porrúa Venero (coords.), 1997, t. 2, pp. 235-260. 
Rabasa, Emilio, La Constitución y la dictadura [1ª ed. 1912], prólogo de Jorge F. Fernández, México, Conaculta, 2002.

Rojas, Beatriz (coord.), Procesos constitucionales mexicanos: la Constitución de 1824 y la antigua constitución, México, Instituto Mora, 2017.

Sánchez de Tagle, Francisco Manuel, Discurso del sr. D. Francisco Tagle en la sesión del 15 de diciembre sobre la creación de un Poder Conservador, México, impreso por J. M. Fernández, 1835.

SÁNChez de TAgLE, Francisco Manuel, Refutación de las especies vertidas en los números 21, 22, 23 del periódico titulado El Anteojo contra el proyecto de la primera ley constitucional, que presentó al Congreso la Comisión de Reorganización, México, Imprenta del Águila, dirigida por José Ximeno, 1835.

"Segundo proyecto de constitución leído en la sesión del 3 de noviembre de 1842”, en Villegas Moreno y Porrúa Venero (coords.), 1997, t. 2, pp. 322-347.

“Sesión secreta extraordinaria del 23 de junio de 1856", en Actas oficiales y minutario de decretos del congreso extraordinario constituyente de 1856-1857, México, El Colegio de México, 1957, p. 288.

SIEYÈs, Emmanuel Joseph, Les discours de Sieyès dans les débats constitutionnels de l'an III (2 et 18 thermidor), París, Hachette, 1939.

Soberanes Fernández, José Luis, Historia del derecho mexicano, México, Porrúa, 2002.

Sordo Cedeño, Reynaldo, El Congreso en la primera república centralista, México, El Colegio de México, Instituto Tecnológico Autónomo de México, 1993.

Straumann, Benjamin, Crisis and Constitutionalism: Roman Political Thought from the Fall of the Republic to the Age of Revolution, Oxford, Oxford University Press, 2016.

Timmermann, Andreas, "El concepto de 'gobierno moderado' como hilo conductor en el constitucionalismo temprano de Hispanoamérica", en Estudios de Historia Moderna y Contemporánea, 44 (2013), pp. 5-25.

Tocqueville, Alexis de, La democracia en América, traducción de Luis A. Cueller, México, Fondo de Cultura Económica, 1957. 
Troper, Michel, "Sieyès et la hiérarchie de normes", en Vincent Denis y Jean Salem (eds.), Figures de Sieyès. Actes du colloque des 5 et 6 mars 2004 organisé à la Sorbonne par le Centre d'histoire des systèmes de pensée moderne el l'Institut d'histoire de la Révolution française (Université Paris I), París, Publications de la Sorbonne, 2008, pp. 25-42.

"Versión paleográfica y facsímil del manuscrito original del Estatuto Orgánico Provisional de la República," en Cruz Barney, 2009, pp. 125-139.

Villegas Moreno, Gloria y Miguel Ángel Porrúa Venero (coords.) Leyes y documentos constitutivos de la nación mexicana. De la crisis del modelo borbónico al establecimiento de la República Federal, México, Instituto de Investigaciones Legislativas, Cámara de Diputados, LXI Legislatura, 1989.

Villegas Moreno, Gloria y Miguel Ángel Porrúa Venero (coords.), Leyes $y$ documentos constitutivos de la nación mexicana. Entre el paradigma político y la realidad, México, Instituto de Investigaciones Legislativas de la Cámara de Diputados, LVI Legislatura, 1997.

"Voto particular de la minoría de la comisión al primer proyecto de Constitución política de la República Mexicana, 25 de agosto de 1842", en Villegas Moreno y Porrúa Venero (coords.), 1997, t. 2, pp. 299-321.

Zimmermann, Eduardo, "Translations of the 'American Model' in Nineteenth Century Argentina: Constitutional Culture as a Global Legal Entanglement", en Duve (ed.), 2014, pp. 385-426. 
